\title{
The effects of the built environment, traffic patterns, and micrometeorology on street level ultrafine particle concentrations at a block scale: Results from multiple urban sites
}

\author{
Wonsik Choi $^{1,2+, *}$, Dilhara Ranasinghe ${ }^{1}$, Karen Bunavage ${ }^{1}$, J.R. DeShazo ${ }^{3}$, Lisa $\mathrm{Wu}^{3}$, Rodrigo Seguel $^{1,4}$, \\ Arthur M. Winer ${ }^{5}$, and Suzanne E. Paulson ${ }^{1,2}$
}

[1]University of California, Los Angeles, Department of Atmospheric and Oceanic Sciences, 405 Hilgard Ave., Los Angeles, California 90095, USA.

[2] University of California, Los Angeles, Institute of the Environment and Sustainability, La Kretz Hall, Suite 300, Los Angeles, California 90095, USA.

[3]University of California, Los Angeles, Luskin Center for Innovation, Luskin School of Public Affairs, 3250 Public Affairs bldg., Los Angeles, California 90095, USA

[4]Center for Environmental Sciences, Faculty of Sciences, University of Chile Las Palmeras 3425 Ñuñoa, Santiago, Chile.

[5]University of California, Los Angeles, Fielding School of Public Health, Environmental Health Sciences Department, 650 Charles Young Dr., Los Angeles, California 90095, USA

+ now at: Pukyong National University, Geo-Science Institute, 45 Yongso-ro, Nam-gu, Busan, Korea

*Correspondence to: Wonsik Choi (wschoi@atmos.ucla.edu) 


\section{Abstract}

This study attempts to explain explicitly the direct and quantitative effects of complicated urban built-environment on near-road dispersion and levels of vehicular emissions at the scale of several city blocks, based on ultrafine particle concentrations ([UFP]). On short timescales, ultrafine particles are an excellent proxy for other roadway emissions. Five measurement sites in the greater Los Angeles with different built environments but similar mesoscale meteorology were explored. After controlling for traffic, for most sampling days and sites, morning [UFP] were higher than those in the afternoon due to limited dispersion capacity combined with a relatively stable surface layer. [UFP] at the intersection corners were also higher than those over the sampling sites, implying that accelerating vehicles around the intersections contributed to [UFP] elevation. In the calm morning, the areal aspect ratio $\left(A r_{\text {area }}\right)$, developed in this study for real urban configurations, showed a strong relationship with block-scale [UFP]. $A r_{\text {area }}$ includes the building area-weighted building height, the amount of open space, and the building footprint. In the afternoon, however, when wind speeds were generally higher and turbulence was stronger, vertical turbulence intensity $\sigma_{w}$ was the most effective factor controlling [UFP]. The surrounding built environment appears to play an indirect role in observed [UFP], by affecting surface level micrometeorology. The effects are substantial; controlling for traffic, differences in $A r_{\text {area }}$ and building heterogeneity were related to differences in [UFP] of factors of two to three among our five study sites. These results have significant implications for pedestrian exposure as well as transit-oriented urban planning.

Keywords: ultrafine particles, built-environment, aspect ratio, turbulence, pedestrian exposure, transitoriented development 


\section{Introduction}

Vehicle emissions are rapidly diluted away from roadways, thus leading to highly spatiallyheterogeneous pollutant concentrations in urban areas. A large fraction of the exposure of many individuals to many pollutants can be attributed to relatively short periods of time spent on and near roadways, which often have highly elevated pollutant concentrations compared to areas at even moderate distances from roadways (Behrentz et al., 2005; Fruin et al., 2004; Marshall et al., 2005; Morawska et al., 2008). However, because of the lack of adequate pollutant measurement data near roadways, studies of health effects attributed to transportation-related air pollutants have generally used freeway or arterial roadway proximity as a proxy for vehicle-related air pollution (Brugge et al., 2007; Ren et al., 2008; Volk et al., 2011; Zhou and Levy, 2007). Despite this rather blunt approach, near roadway pollution studies have shown moderate increases in a long list of adverse health outcomes, including increased incidence of cancer (Pearson et al., 2000), asthma (Janssen et al., 2003), general mortality (Hoek et al., 2002), , heart attacks (Tonne et al., 2007), autism (Volk et al., 2011), pre-term birth (Ren et al., 2008) and other adverse outcomes associated with proximity to roadways.

Of a wide range of particle- and gas-phase species contained in fresh vehicular emissions, ultrafine particles (UFP; particles smaller than 100nm in diameter) are one of the best tracers of near-roadway pollution, due to their large dynamic concentration ranges $\left(10^{3}\right.$ to $10^{6}$ particles $\mathrm{cm}^{-}$ ${ }^{3}$ ) and relatively short life time, which results in low and steady background concentrations (Capaldo and Pandis, 2001; Choi et al., 2013), and the availability of high time resolution (1s) instrumentation that allows resolution of pollutant gradients controlled by complex dispersion .

Despite an increasing amount of literature related to near-roadway exposures, surprisingly little is known about how to proactively design and plan for these transit environments in order to minimize air pollution exposures. Therefore, it is desirable to develop a set of comprehensive 
recommendations on how to reduce pedestrian and residential air pollution exposures that will aid transportation and urban planners make future development plans. These may include traffic controls and urban building configuration, which impact emissions and dispersion, respectively. Within the transit environment, urban planners also decide spatially where pedestrian density will be greatest through their choices of where to site transit stops, sidewalks, and parks.

Several studies investigating the influence of the built environment on street level concentrations have been published recently, mostly focusing on deep street canyons and a few others. Four recent studies have taken the first step towards understanding dispersion of trafficrelated pollutants in urban areas with inhomogeneous building morphology, which is our focus (Boarnet et al., 2011; Boogaard et al., 2011; Buonanno et al., 2011; Pirjola et al., 2012). Buonanno et al. (2011) focused on particles, including UFP, measured in four different street canyons with different building height-to-street width ratios $(\mathrm{H} / \mathrm{W}=0.5$ to 1.3$)$ in a town in central Italy; Pirjola et al. (2012) investigated dispersion of traffic emissions (focusing on UFP) in three different micro-environments (but with similar H/W 0.5) in Helsinki, Finland; Boogard et al. (2011) conducted an extensive study in the Netherlands in which five species, including particle number concentrations and black carbon, were measured over 6 weeks at 8 urban roadside locations in five cities; and Boarnet et al. (2011) examined the factors governing $\mathrm{PM}_{2.5}$ measured on sidewalks next to arterial roadways in five cities in southern California.

Of these studies, Boogard et al. (2011) and Boarnet et al. (2011) conducted stationary measurements of roadway pollutants, whereas Buonanno et al. (2011) and Pirjola et al. (2012) used a mobile platform to characterize UFP concentrations with a high temporal resolution. Boogard et al. (2011) reported the two streets with buildings lining one or both sides of the streets showed the largest road contributions although their results did not discern the roles of 
meteorology, detailed building morphologies, and emissions. Boarnet et al. (2011) suggested the most effective controlling factors for sidewalk $\mathrm{PM}_{2.5}$ concentrations are daily variations, time of day, winds, and temperature. They also argued that traffic and built environment variables accounted for only a small amount of variation, although they are statistically significant. However, their built environment variables were classified rather than quantified. After accounting for these most effective controlling factors, they concluded that street canyons with higher than 5-story buildings are related to high $\mathrm{PM}_{2.5}$ concentrations, and adjacent paved lots were negatively associated with concentrations. Buonanno et al. (2011) and Pirjola et al. (2012) using mobile platform measurements, concluded that the surrounding built environment significantly affects pollutant concentrations in urban microenvironments by changing the dispersion. However, both studies considered only the averaged H/W and did not consider the detailed information of built environment such as the gaps between buildings and open spaces if any, and also did not quantitatively examine the role of built environment in pollutant concentrations.

While these studies provide insight into air pollution in built environments, the measurements lack the spatial resolution and completeness to discern contributions of detailed urban morphology and traffic control at a level that might inform highly-local planning decisions about the built environment and traffic flow regimes. Minimizing exposure to transportationrelated air pollution is not fully considered currently in the process of planning for transitoriented developments (TOD) (Haughey and Sherriff, 2010).

There are several relevant spatial scales to the investigation of the built environment with pollutant concentrations. Here we focus on a spatial scale of several city blocks. We develop quantitative links among the variables that control dispersion in complex urban environments, 
including building morphology, traffic flow rates, and micrometeorology. We consider data from five sites in the greater Los Angeles area, each with similar fleet composition and synoptic meteorology, but markedly different built environments and traffic flow patterns. Measurements were performed in both the early morning and mid-afternoon, which have significantly different atmospheric stability and wind profiles.

\section{Methods}

\subsection{Sampling sites and built-environmental characteristics}

Extensive field experiments, including mobile and stationary measurements of vehicular pollutants and traffic, were conducted at four sites in and around downtown Los Angeles (DTLA) and at a site in Temple City, located $20 \mathrm{~km}$ east of DTLA, for 16 days between July and November of 2013 (Fig. S1; Table 1). Each sampling site represents a distinct urban built environment with a different building morphology (e.g., building heights and areas, intersection areas, street widths, building densities and homogeneity) and traffic patterns (e.g. flow rates, traffic densities, fleet compositions, traffic light cycle periods). Each sampling site covered a 2by-2 (or 3) block area centered on a main intersection where stationary sampling of pollutants and traffic monitoring were conducted, depending on availability of instruments. All sites were located more than $800 \mathrm{~m}$ from the nearest freeway, well outside the range of freeway influence during daytime. As UFP are relatively short lived and upwind areas for all sites consist of similarly developed urban areas for many kilometers, the influence of areas farther than the neighbouring several streets are not expected to be discernable in this dataset.

The Broadway and $7^{\text {th }}$ St. site (Site1) located in DTLA $\left(34.04519^{\circ} \mathrm{N} / 118.25639^{\circ} \mathrm{W}\right)$ is a street canyon environment surrounded by tall commercial buildings on both sides of the streets. Building heights were $>40 \mathrm{~m}$ with little, if any, gaps between buildings. The block lengths/street 
widths (measured from building face to building face on the two sides of the street) of Broadway and $7^{\text {th }}$ streets are $190 \mathrm{~m} / 26 \mathrm{~m}$ and $100 \mathrm{~m} / 22 \mathrm{~m}$, respectively (Table2). The Olive and $12^{\text {th }}$ St. site (Site2) is located $1 \mathrm{~km}$ southeast of Site $1\left(34.03943^{\circ} \mathrm{N} / 118.26226^{\circ} \mathrm{W}\right)$. The intersection is occupied by a $130 \mathrm{~m}$ tall isolated skyscraper surrounded by large open spaces and low-story buildings. This site had low traffic flows and short queues. The block lengths/street widths of Olive and $12^{\text {th }}$ St. are $180 \mathrm{~m} / 28 \mathrm{~m}$ and $95 \mathrm{~m} / 17 \mathrm{~m}$, respectively. The Vermont and $7^{\text {th }}$ St. site (Site 3 ) located $4 \mathrm{~km}$ northwest of Sitel $\left(34.05976^{\circ} \mathrm{N} / 118.29164^{\circ} \mathrm{W}\right)$ is similar to the Site 2 , but surrounding buildings are more densely patched and open spaces are smaller. In addition, Vermont Ave. in Site3 is one of the busiest arterials in the Los Angeles area. The block lengths $/$ street widths of Vermont Ave. and $7^{\text {th }}$ St. are $190 \mathrm{~m} / 30 \mathrm{~m}$ and $95 \mathrm{~m} / 25 \mathrm{~m}$, respectively. The Wilshire and Carondelet St. site (medium-sized buildings on one side, Site4) is located 3km northwest from Site 1 and $1 \mathrm{~km}$ east from Site $3\left(34.06012^{\circ} \mathrm{N} / 118.28054^{\circ} \mathrm{W}\right)$. Site4 represents a typical city environment in the Los Angeles area, consisting of a mixture of open space and moderately-sized buildings. The whole block of the south side of Wilshire Blvd. is occupied by $30 \mathrm{~m}$ and $50 \mathrm{~m}$ tall buildings while the north side is open or occupied by 5 or $10 \mathrm{~m}$ tall buildings. The block lengths/street widths of Site 4 are $75 \mathrm{~m} / 37 \mathrm{~m}$ (Wilshire) and 160m/17m (Carondelet). Finally, the Temple City and Las Tunas Blvd. site (a low and flat residential site, Site5) in Temple City $\left(34.10669^{\circ} \mathrm{N} / 118.06090^{\circ} \mathrm{W}\right)$ is surrounded mostly by one-story single family homes and small commercial buildings ( $<6 \mathrm{~m}$ in height). The block lengths/street widths of Temple City and Las Tunas Blvd. are $175 \mathrm{~m} / 24 \mathrm{~m}$ and $115 \mathrm{~m} / 30 \mathrm{~m}$, respectively. 


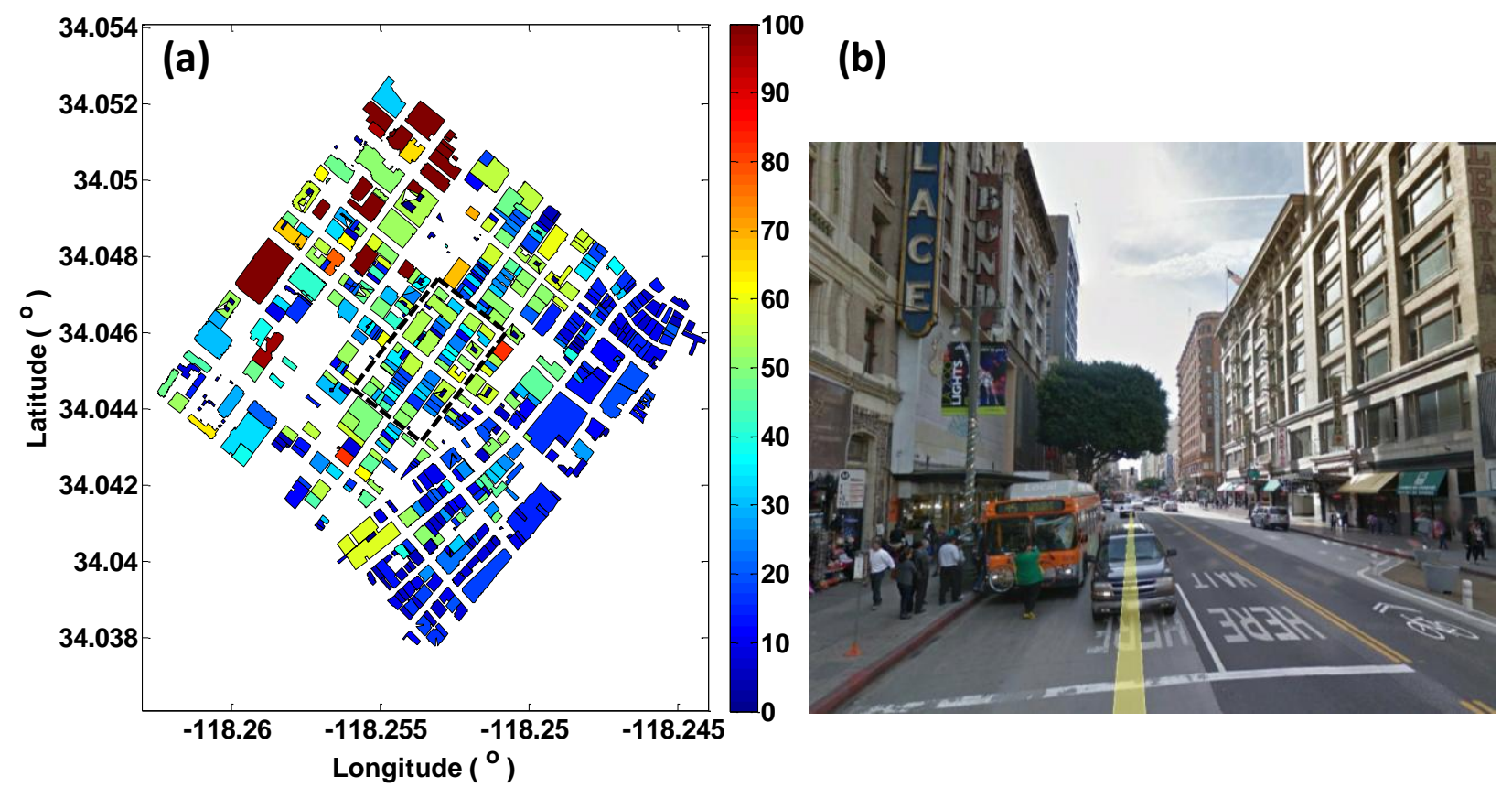

Figure 1. (a) Map of building heights and morphology in downtown Los Angeles. Dashed black line shows the sampling area centered by the Broadway St. (Northeast-Southwest direction) \& $7^{\text {th }} \mathrm{St}$.

intersection.Color bar represents the building heights in meters. (b) The street view on Broadway St. captured in Google Earth. The building distributions and street views for the other sites are presented in the Supplementary Information, Fig. S2. 
Table 1. Description of field measurements including built-environments, measurement dates, instrumentation, and sampling design

\begin{tabular}{|c|c|c|c|c|}
\hline Sites & Built-Env. & Date & Instrumentation & Sampling strategy \\
\hline \multirow{2}{*}{$\begin{array}{l}\text { Broadway } \\
\quad \& \\
7^{\text {th }} \text { St. } \\
\text { Site1 }\end{array}$} & \multirow{2}{*}{$\begin{array}{l}\text { Street canyon with tall } \\
\text { buildings }(H>40 m) \text { at both } \\
\text { side of the street. } \\
\text { Highly trafficked on both } \\
\text { streets. }\end{array}$} & $\begin{array}{l}7 / 1 \\
7 / 2 \\
7 / 3 \\
7 / 5\end{array}$ & $\begin{array}{l}\text { [1] ARB-MMP; } \\
2 \text { DM; } 2 \text { sonic tower (roof \& surface); } \\
4 \text { traffic recording cameras }\end{array}$ & $\begin{array}{l}\text { [A] } 2 \text { DM were paired across the street, } \\
\text { staying about } 5 \mathrm{~min} \text {. at mid-blocks and } \\
\text { intersections (quasi-stationary) }\end{array}$ \\
\hline & & $11 / 13$ & $\begin{array}{l}\text { [2]Lite-MMP; } \\
3 \text { DM; CPC; OPS; } 2 \text { surface sonic tower; } \\
4 \text { traffic cam }\end{array}$ & $\begin{array}{l}\text { [B] } 2 \text { DM were stationary at the Intersections } \\
1 \text { CPC\&OPS stayed at the sonic tower } \\
1 \text { DM stationary across the sonic tower }\end{array}$ \\
\hline \multirow[b]{2}{*}{$\begin{array}{l}\text { Temple City } \\
\quad \& \\
\text { Las Tunas } \\
\quad \text { Site5 }\end{array}$} & \multirow{2}{*}{$\begin{array}{l}\text { All short buildings }(\mathrm{H}<6 \mathrm{~m}) \\
\text { around the site } \\
\text { Moderately trafficked } \\
\text { (Las Tunas }>\text { Temple) }\end{array}$} & $8 / 6$ & [1] but 1 sonic tower & {$[A]$} \\
\hline & & $\begin{array}{l}9 / 17 \\
9 / 18\end{array}$ & $\begin{array}{l}\text { [3] Lite-MMP; } \\
1 \text { DM; CPC; OPS; } 2 \text { sonic tower (roof \& } \\
\text { surface); } \\
4 \text { Traffic cameras }\end{array}$ & $\begin{array}{l}\text { [C] } 1 \text { DM at intersection (staying } 5 \text { light } \\
\text { cycles at each corner) and CPC \& OPS stayed } \\
\text { next to sonic tower }\end{array}$ \\
\hline \multirow{2}{*}{$\begin{array}{l}\text { Olive } \\
\& \\
12^{\text {th }} \text { St. } \\
\text { Site2 }\end{array}$} & \multirow{2}{*}{$\begin{array}{l}\text { One tall building at one } \\
\text { corner of intersection }+ \\
\text { many open space } \\
\text { Sparse traffic }\end{array}$} & $9 / 24$ & \multirow[t]{2}{*}[3]{} & {$[C]$} \\
\hline & & $9 / 25$ & & $\begin{array}{l}{[C] \text { but } 1 \mathrm{DM} \text { was stationary across the sonic }} \\
\text { tower }\end{array}$ \\
\hline \multirow{2}{*}{$\begin{array}{l}\text { Vermont } \\
\& \\
7^{\text {th }} \text { St. } \\
\text { Site3 }\end{array}$} & \multirow{2}{*}{$\begin{array}{l}\text { One tall building at } \\
\text { intersection } \\
\text { Large traffic on Vermont }\end{array}$} & $\begin{array}{l}10 / 7 \\
10 / 14\end{array}$ & [3] & [C] \\
\hline & & $11 / 18$ & {$[2]$} & {$[B]$} \\
\hline \multirow{3}{*}{$\begin{array}{l}\text { Wilshire } \\
\quad \& \\
\text { Carondelet } \\
\text { Site4 }\end{array}$} & \multirow[t]{3}{*}{$\begin{array}{l}\text { Two tall buildings } \\
\text { Modest traffic on Wilshire }\end{array}$} & $11 / 1$ & [2] & $\begin{array}{l}{[A] \text { and additional DM was stationary across }} \\
\text { the sonic tower }\end{array}$ \\
\hline & & $11 / 6$ & [2] & {$[B]$} \\
\hline & & $11 / 20$ & {$[2]$} & {$[B]$} \\
\hline
\end{tabular}

ARB-MMP: California Air Resources Board mobile monitoring platform

Lite-MMP: Electric vehicle equipped with a DiSCmini

$D M$ : DiSCmini ultrafine particle counter, CPC: condensation particle counter, OPS: Optical particle size 
Table 2. Built environments in the mobile sampling areas.

\begin{tabular}{|c|c|c|c|c|c|}
\hline & $\begin{array}{c}\text { Broadway } \\
\& \\
7 \text { th } \\
\text { (Site1) } \\
\end{array}$ & $\begin{array}{l}\text { Olive St. } \\
\& \\
12^{\text {th }} \text { St. } \\
(\text { Site } 2)\end{array}$ & $\begin{array}{l}\text { Vermont } \\
\& \\
7^{\text {th }} \text { St. } \\
\text { (Site3) }\end{array}$ & $\begin{array}{c}\text { Wilshire } \\
\& \\
\text { Carondelet } \\
\text { (Site4) }\end{array}$ & $\begin{array}{c}\text { Temple City } \\
\& \\
\text { Las Tunas } \\
\text { (Site5) } \\
\end{array}$ \\
\hline \# of buildings & 59 & 34 & 90 & 44 & 143 \\
\hline Max. building height $(\mathrm{m})$ & 58 & 129 & 80 & 57 & 8 \\
\hline $\begin{array}{l}\text { Mean building height, } H_{\text {bldg }} \\
\text { (m) }\end{array}$ & 34 & 21 & 11 & 18 & 5 \\
\hline $\begin{array}{l}\text { Bldg area weighted height, } \\
H_{\text {area }}(m)\end{array}$ & 40 & 42 & 25 & 24 & 6 \\
\hline $\begin{array}{l}\text { Bldg. homogeneity, } \\
H_{\text {area }} / H_{\text {bldg }} \text { (dimensionless) } \\
(1=\text { perfectly homogeneous) }\end{array}$ & 1.16 & 2.01 & 2.21 & 1.39 & 1.09 \\
\hline $\begin{array}{l}\text { Mean building ground area } \\
\left(\mathrm{m}^{2}\right)\end{array}$ & 1,030 & 1,395 & 585 & 992 & 225 \\
\hline Street width $(m)$ & $\begin{array}{l}26(\mathrm{BW}) / \\
22\left(7^{\mathrm{th}}\right)\end{array}$ & $\begin{array}{l}28 \text { (Olive) / } \\
17\left(12^{\text {th }}\right)\end{array}$ & $\begin{array}{l}30(\text { Ver }) / \\
25\left(7^{\text {th }}\right)\end{array}$ & $\begin{array}{l}17 \text { (Car) / } \\
37 \text { (Wil) }\end{array}$ & $\begin{array}{c}24(\mathrm{TC}) / \\
30(\mathrm{LT})\end{array}$ \\
\hline $\begin{array}{l}\text { Simple Aspect ratio } \\
\left(H_{\text {area }} / W_{\text {street }}\right)\end{array}$ & 1.7 & 1.9 & 0.9 & 0.9 & 0.2 \\
\hline Block length $(m)$ & $\begin{array}{c}190(\mathrm{BW}) / \\
100\left(7^{\mathrm{th}}\right)\end{array}$ & $\begin{array}{l}180(\text { Olive }) / \\
95\left(12^{\text {th }}\right)\end{array}$ & $\begin{array}{l}190(\text { Ver }) / \\
95\left(7^{\text {th }}\right)\end{array}$ & $\begin{array}{l}160 \text { (Car) / } \\
75 \text { (Wil) }\end{array}$ & $\begin{array}{l}175(\mathrm{TC}) / \\
115(\mathrm{LT})\end{array}$ \\
\hline Ratio occupied by bldg. & 0.72 & 0.42 & 0.33 & 0.46 & 0.30 \\
\hline
\end{tabular}

The sites are numerically ordered based on the height of urban canopy (mean building areaweighted building heights); lower numbers indicate higher building morphology; e.g., Sitel has a street canyon and tall buildings; Site 5 has a low/flat urban configuration (Table 2). The distributions of buildings and building morphology around sampling sites are presented in Supplementary Information (SI) (Figs. 1 and S2 and Table 2).

\subsection{Instrumentation and Sampling Design}

A fully-equipped Toyota RAV4 electric sub-SUV, maintained by the California Air Resources Board (CARB), served as a mobile monitoring platform (ARB-MMP). A suite of fast 
response instruments in the ARB-MMP measures various air pollutants with $1 \mathrm{sec}$ temporal resolution, including UFP number concentrations (TSI, CPC 3007) and size distributions (TSI, FMPS 3009), nitrogen oxides (NOx) (Teledyne, API 200E), carbon monoxide (CO) (Teledyne, API 300E), carbon dioxide $\left(\mathrm{CO}_{2}\right)$ (LI-COR, LI-820), particle-bound polycyclic aromatic hydrocarbons (PB-PAH) (EcoChem PAS 2000), particulate matter with aerodynamic diameters less than $2.5 \mu \mathrm{m}\left(\mathrm{PM}_{2.5}\right)$ (TSI DustTrak 8520), and black carbon (BC) (Magee Scientific Aethalometer). The ARB-MMP has been used in a series of near/on road air quality studies and detailed information is found elsewhere (Choi et al., 2012; Choi et al., 2013; Hu et al., 2012; Kozawa et al., 2009, and others). When the ARB-MMP was not available due to maintenance, an electric vehicle (Chevrolet Volt or Nissan Leaf) equipped with a DiSCmini was used instead. The DiSCmini is a fast diffusion size classifier that measures UFP number concentration (20-700 $\mathrm{nm}$ size range) and the mean size of UFP collected every second. Many of the measurements were performed with a DiSCmini hand held particle counter (Matter Aerosol AG).

As this instrument is relatively new, evaluations are only available for laboratory-generated nanoparticles under controlled indoor conditions (Bau et al., 2015; Mills et al., 2013). We provide additional inter-comparison data for our urban conditions. Briefly, for about 5 to 10 minutes before and after the measurements of all sessions (A.M. and P.M.), all particle number counters (4 DiSCminis and a CPC) were placed at the same location near roadways for intercomparison under various atmospheric conditions. All five particle instruments were very stable over time; while there were some moderate deviations from 1:1 slopes (due to the individual instruments and /or the inlet tubing). The slopes were not observed to drift over time. The readings from all instruments agreed consistently within ca. $20 \%$ with excellent linearities $\left(\mathrm{R}^{2}\right.$ $\approx 0.9$ or better; see SI 2). Due to the upper limit of detection of CPC $\left(10^{5}\right.$ particles $\left.\cdot \mathrm{cm}^{-3}\right)$, the 
comparison between CPC and DiSCmini was made with [UFP] less than $8 \times 10^{4}$ particles $\cdot \mathrm{cm}^{-3}$ (which excludes less than $4 \%$ of the total dataset; SI 2.3). An inlet tube (1.5 m long Tygon tubing supplied by provider) installed on the DiSCmini caused a 2 sec delay (easily corrected), and diffusional and electrostatic particle losses due to the inlet tubing was estimated as 15\% (SI 2.1). A comparison of the mean particle diameter between Scanning Mobility Particle Sizer (SMPS, TSI 3080) and DiSCmini was made separately on a rooftop at UCLA with an ambient air and showed perfect agreement and good linearity (with a slope of 1.00 and R2=0.67; SI 2.4). In this study, all DiSCmini data were converted to corresponding CPC values based on the slopes of 1:1 comparisons (Eqs. S1 S4) so that the measured [UFP] can be compared directly because the CPC has been more widely and conventionally used in UFP air pollution studies. Detailed intercomparison results are presented in SI 2.

In all cases, the inlet for instruments was located on the passenger side of the vehicle near the roofline (about $1.5 \mathrm{~m}$ height from the ground, matching the height of the pedestrians breathing zone), in as close proximity to the sidewalk as practical (roughly within $2-5 \mathrm{~m}$ ). Thus, the concentrations measured by the MMP closely reflect the pedestrian exposure levels near the roadways. The same post-data processes described in Choi et al. (2012) were performed to synchronize instruments and precisely account for the response time (a time-lag correlation method on a twice-daily basis).

A GPS (GPSMAP 76CS, Garmin or BT-Q1000XT, Qstarz International Co., Ltd., depending on availability) was employed to record MMP positions every second, and the corrections of the GPS data were made using a line reference technique as described in detail in a companion paper (Ranasinghe et al., 2015). In this study, however, site-by-site comparisons are the main focus, and thus the highly spatially resolved data of the MMP were not used. 
A combination of mobile and stationary measurements was conducted depending on the availability of instruments (Table 1). Intensive measurements were conducted for $\sim 2$ hrs twice a day, once in the early morning (06:00 - 09:00) and once in mid-afternoon (13:00 - 17:00). These periods represent two distinct meteorological conditions: limited mixing in the mornings vs. vigorous vertical mixing due to surface heating in the afternoons. A schematic of the sampling design is shown in Fig. 2. For the entire sampling period, the MMP drove four-leaf clover shaped routes around the main intersection, typically completing 7 to 12 repeats of the route for each morning or afternoon.

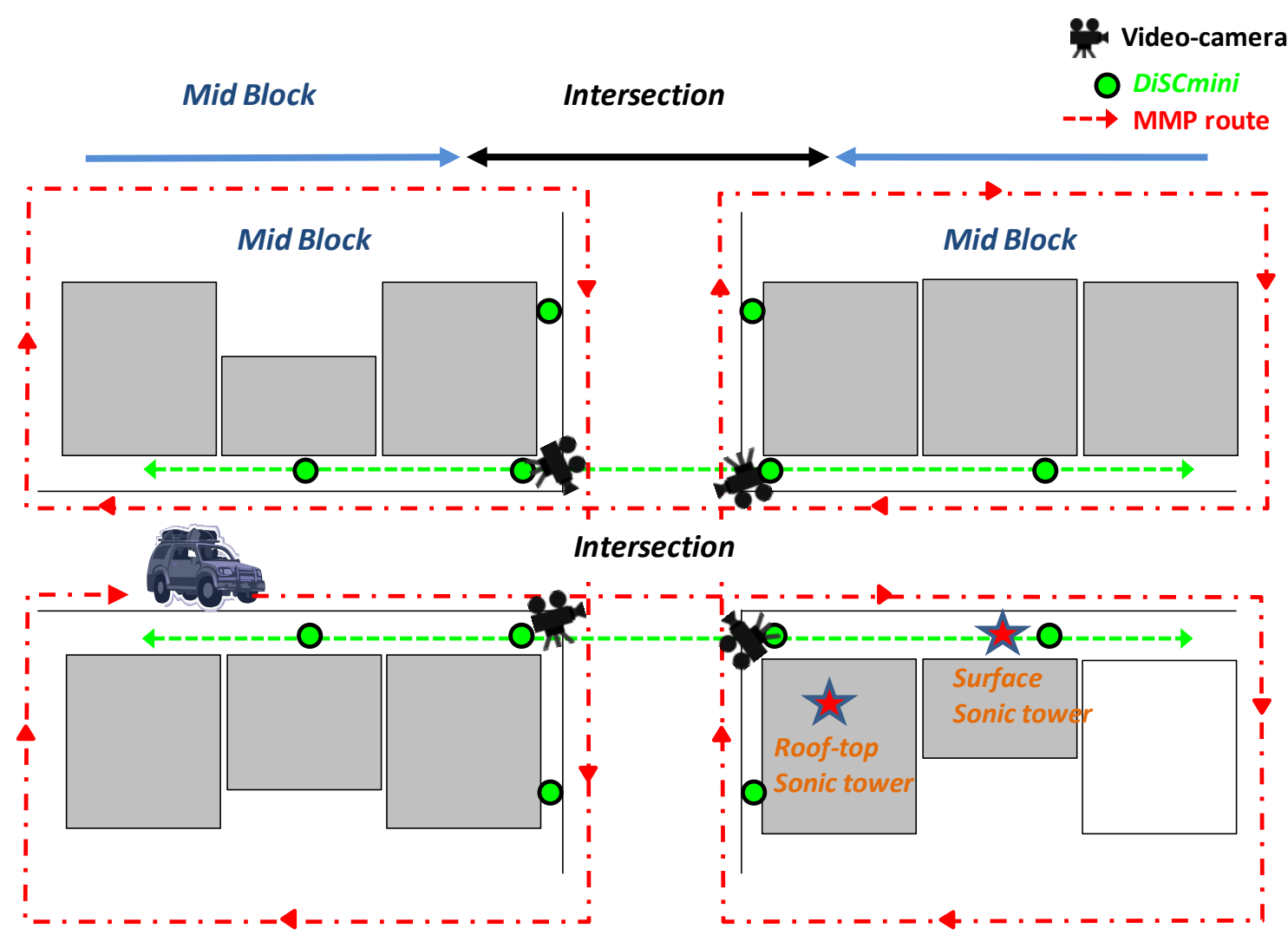

Figure 2. A schematic of the intersection sampling design. Green circles denote the location of a DiSCmini pair (across the street) for 5-minute stationary measurements. Red stars represent the location of surface and roof-top (only when roof-top access was possible) sonic towers. The actual positions and spatial scales are different from this illustration. 
To supplement mobile measurements, a pair of UFP counters (DiSCmini) were deployed on pedestrian sidewalks. The DiSCmini pair, being positioned across the street from one another, sampled for 5 to 10 minutes at the mid-blocks and intersections on one street and then moved to other mid-block or intersection locations (Fig. 2). The objective of mobile sampling was to obtain highly resolved spatial distributions of pollutant concentrations, whereas paired measurements of UFP are useful for investigating street canyon and other effects caused by incanopy circulation in different built environments. Also, paired DiSCmini measurements were taken in the immediate location of pedestrians at a height near breathing zones and therefore sampled direct pedestrian exposure to vehicular emissions.

\subsection{Meteorological, Traffic and Built-environment Parameters}

Surface meteorological data were obtained from three-axis sonic anemometers $(10 \mathrm{~Hz}$ CSAT3, Campbell Sci. Inc. and $21 \mathrm{~Hz}$ WindMaster, Gill Instruments Ltd.) installed on pedestrian sidewalks, $3 \mathrm{~m}$ above the ground level. Although we cannot separate vehicle-induced turbulence and building effects from ambient turbulence, the surface meteorological and micrometeorological information obtained here indicate the overall meteorological conditions within the building canopies in urban environments. Considered surface micrometeorological parameters include the mean wind speed, wind direction, friction velocity, three-directional wind fluctuations $\left(\sigma_{u}, \sigma_{v}\right.$, and $\left.\sigma_{w}\right)$, and turbulence kinetic energy. The detailed procedure for calculating these micrometeorological parameters is presented in SI 3.

Building information, including building area, height, and location, was extracted from LARIAC2 Geographic Information System data (LARIAC, 2009). Because the scope of this study was to compare pollutant levels site-by-site with various collective characteristics of built 
environments, we additionally derived the customized building parameters at sampling area scale from GIS building information, including building-area-weighted building height, building density, heterogeneity and areal aspect ratio. The quantified built-environmental parameters for each sampling site are discussed in more detail in Section 3.3.

At the four corners of each central intersection (Fig. 2), directional traffic (north-, south,east-, and west-bound) and traffic light signal status were recorded with four video cameras to provide highly detailed traffic information for the sampling periods. Traffic video files were reviewed and coded for the traffic parameters at 1 second resolution. The traffic parameters are: traffic light status (red, green, yellow), the number of passenger vehicles, heavy/medium duty vehicles and buses passing the central intersection, and the number of each type of vehicle waiting in queues during red lights. The 1-second resolution traffic data were used in a high resolution statistical model and will be presented in the separate publication. In the present study, the average period of traffic light cycles $\left(P_{T L}\right)$, mean traffic flow rates for a $P_{T L}\left(\right.$ cars $\left.\cdot \mathrm{min}^{-1}\right)$, and mean number of cars in a queue $\left(L_{q u e}\right)$ were calculated from the high resolution traffic codes and compared with the variations in UFP number concentrations of the five sampling sites.

\section{Determination of Characteristics of Traffic, Meteorology, and Built Environments}

\subsection{Traffic}

Observed traffic characteristics at each site are shown in Table 3. The basic traffic light periods were 69 or 89 seconds; these changed actively depending on traffic conditions. Traffic rates (vehicles $\mathrm{min}^{-1}$ ) were comparable or higher in the afternoon sessions compared to morning sessions, except at Site2. The highest traffic rates were observed at Site 3 and Site5 in both the mornings and afternoons. Although the traffic rates were comparable between Site 3 and Site5, traffic density at Site 3 was significantly higher due to unequal distributions of traffic between the 
two streets and the denser arterial-street-network in this commercial/business district. Of the five sampling sites, Site1 and Site 5 had equal traffic between North-South and East-West streets and Site3 and Site4 showed significant disparity in traffic rates between N-S and E-W streets. Site2 also had unequal traffic distributions, but the overall traffic rate was minimal for the whole day. Heavy- and medium-duty (HD and MD) vehicles were encountered infrequently for all sampling sites $\left(<1.5\right.$ vehicle $\left.\cdot \mathrm{min}^{-1}\right)$. Thus, for all study areas, gasoline vehicles were dominant, accounting for 95 to $98 \%$ of the total traffic rates except one case (for the afternoon on 9/25/2013, gasoline vehicles accounted for $90 \%$ of traffic rate due to very few passenger vehicles at this time and location. Based on consistent fleet compositions for the entire sampling sites and infrequent HD and MD traffic rates, we do not separate a fleet composition in further discussion. We feel that to attempt to account for slight differences in fleet composition between the sites would only introduce more errors, particularly because at the time of the field study the emissions from the HDDT fleet were changing rapidly due to a suite of new regulations. Further, observationally the fleet composition between these sites in terms of vehicle makers, models, and years was similar. Data from a more affluent area were not included in this study partly because of this issue, although the dominant factor in that decision was that the sampling route design was substantially different. 
Table 3. Characteristic traffic patterns observed for each site for measurement periods. Values in parentheses are standard deviations.

\begin{tabular}{|c|c|c|c|c|c|c|c|c|c|c|}
\hline \multirow[b]{2}{*}{ Date } & \multicolumn{5}{|c|}{ Morning } & \multicolumn{5}{|c|}{ Afternoon } \\
\hline & $\begin{array}{l}\text { Light } \\
\text { cycle } \\
\text { sec }\end{array}$ & $\begin{array}{l}\text { Traffic } \\
\text { rate } \\
\# \cdot \min ^{-1}\end{array}$ & $\begin{array}{l}\text { HDV/ } \\
\text { MDV } \\
\text { \# /cycle }\end{array}$ & $\begin{array}{l}\text { Queue } \\
\text { length } \\
\# \\
\text { /cycle }\end{array}$ & $\begin{array}{l}\text { Traffic } \\
\text { Ratio }\end{array}$ & $\begin{array}{l}\text { Light } \\
\text { cycle } \\
\text { sec }\end{array}$ & $\begin{array}{l}\text { Traffic } \\
\text { rate } \\
\# \cdot \mathrm{min}^{-1}\end{array}$ & $\begin{array}{l}\text { HDV/ } \\
\text { MDV } \\
\# / \text { cycle }\end{array}$ & $\begin{array}{l}\text { Queue } \\
\text { length } \\
\# \\
\text { /cycle }\end{array}$ & $\begin{array}{l}\text { Traffic } \\
\text { Ratio }\end{array}$ \\
\hline & \multicolumn{10}{|c|}{ Sitel (Street Canyon) } \\
\hline $7 / 1$ & $69(4)$ & $29(2)$ & $1.4(1.2)$ & $20(5)$ & 0.47 & & & & & \\
\hline $7 / 2$ & & & & & & $89(4)$ & $41(8)$ & $0.9(0.9)$ & $31(8)$ & 0.51 \\
\hline $7 / 3$ & $69(5)$ & $29(6)$ & $1.0(1.2)$ & $18(5)$ & 0.44 & $89(3)$ & $43(8)$ & $0.9(0.9)$ & $29(5)$ & 0.52 \\
\hline $7 / 5$ & $70(4)$ & $22(5)$ & $0.9(1.1)$ & $12(4)$ & 0.48 & $89(4)$ & $35(5)$ & $0.5(0.9)$ & $29(6)$ & 0.49 \\
\hline \multirow[t]{2}{*}{$11 / 13$} & $69(2)$ & $34(5)$ & $0.9(1.0)$ & $21(5)$ & 0.56 & $69(1)$ & $28(5)$ & $1.4(1.2)$ & $20(5)$ & 0.47 \\
\hline & \multicolumn{10}{|c|}{ Site2 (Isolated skyscraper with low traffic rates) } \\
\hline $9 / 24$ & $69(2)$ & $22(7)$ & $0.6(0.8)$ & $3(2)$ & 0.81 & $77(10)$ & $12(3)$ & $0.6(0.6)$ & $2(1)$ & 0.75 \\
\hline \multirow[t]{2}{*}{$9 / 25$} & $69(3)$ & $27(7)$ & $0.9(0.9)$ & $6(3)$ & 0.87 & $69(1)$ & $10(3)$ & $1.0(0.7)$ & $3(2)$ & 0.75 \\
\hline & \multicolumn{10}{|c|}{ Site3 (Isolated skyscrapers with high traffic rates) } \\
\hline $10 / 7$ & $89(3)$ & $47(6)$ & $2.0(1.2)$ & $22(6)$ & 0.81 & $89(1)$ & $51(7)$ & $1.4(1.1)$ & $28(6)$ & 0.75 \\
\hline $10 / 14$ & $91(12)$ & $47(7)$ & $1.4(1.1)$ & $27(7)$ & 0.81 & $90(11)$ & $47(6)$ & $1.2(1.0)$ & $27(7)$ & 0.77 \\
\hline \multirow[t]{2}{*}{$11 / 18$} & $89(1)$ & $54(7)$ & $1.6(1.1)$ & $33(7)$ & 0.77 & $89(2)$ & $51(6)$ & $1.1(1.0)$ & $29(6)$ & 0.76 \\
\hline & \multicolumn{10}{|c|}{ Site4 (One-side medium height buildings) } \\
\hline $11 / 1$ & $110(44)$ & $30(5)$ & $1.2(1.3)$ & $4(2)$ & 0.95 & $98(34)$ & $29(9)$ & $1.0(0.9)$ & $5(2)$ & 0.94 \\
\hline $11 / 6$ & $100(30)$ & $35(6)$ & $0.8(0.9)$ & $4(2)$ & 0.93 & $107(36)$ & $29(4)$ & $0.8(0.9)$ & $6(3)$ & 0.92 \\
\hline \multirow[t]{2}{*}{$11 / 20$} & $100(30)$ & $35(6)$ & $0.9(0.9)$ & $5(3)$ & 0.91 & $97(23)$ & $30(5)$ & $1.1(1.0)$ & $6(2)$ & 0.89 \\
\hline & \multicolumn{10}{|c|}{ Site5 (Low and Flat) } \\
\hline $8 / 6$ & $71(6)$ & $45(7)$ & $1.7(1.9)$ & $24(9)$ & 0.44 & $79(9)$ & $64(10)$ & $1.2(1.1)$ & $50(15)$ & 0.48 \\
\hline $9 / 17$ & & & & & & $70(8)$ & $49(10)$ & $1.6(1.5)$ & $27(8)$ & 0.46 \\
\hline $9 / 18$ & $81(8)$ & $61(10)$ & $1.8(1.6)$ & $41(13)$ & 0.49 & $69(1)$ & $55(9)$ & $1.4(1.1)$ & $33(10)$ & 0.48 \\
\hline
\end{tabular}

\subsection{Meteorology}

Observed meteorology including detailed surface micrometeorology is summarized in Table 4 and Fig. S7 in SI 3. Morning meteorology was generally calm for all sampling sites, with mean wind speeds below $1.4 \mathrm{~m} \cdot \mathrm{s}^{-1}$ with $1 \sigma$ values within $0.4 \mathrm{~m} \cdot \mathrm{s}^{-1}$; with the exception of $9 / 25 / 2013$ at Site 2 , where the wind was exceptionally strong at $1.9( \pm 0.6) \mathrm{m} \cdot \mathrm{s}^{-1}$. Friction velocity $\left(u_{*}\right)$, vertical wind fluctuation $\left(\sigma_{\mathrm{w}}\right)$, and turbulence kinetic energy $(T K E)$ appeared to be similar 
among the sites in the morning (Table 4). In the afternoon, wind speeds increased up to $3.3 \mathrm{~m} \cdot \mathrm{s}^{-1}$ with $1 \sigma$ values within $0.6 \mathrm{~m} \cdot \mathrm{s}^{-1}$. Thus, meteorological conditions were not variable for 2 -hour sampling periods. Turbulence parameters for afternoon sampling periods varied more widely between sites. For instance Site1, Site4, and Site5 had a less turbulent surface atmosphere than Site2 and Site3. As noted earlier Site2 and Site3 have more heterogeneous building morphology with one or two isolated tall buildings together with large open areas and/or low building areas than other sites. This heterogeneous building configuration may generate more intense turbulence near the intersections as discussed later in Section 4.4.2.

\subsection{Built environments}

To quantitatively investigate the built-environmental effects on street-level pollutant distributions, the key built-environmental factors were defined and calculated: the number of buildings in the sampling area; the mean building height (Eq. 1); building area-weighted height (Eq. 2); building heterogeneity (Eq. 3), street width, block length, and ratio of the area occupied by buildings to the total sampling area (building density; Eq. 4):

Mean building height, $H_{\text {bld }}=\frac{\sum_{i=1}^{N} H_{i}}{N}$

Building area-weighted building height, $H_{\text {area }}=\frac{\sum_{i=1}^{N}\left(S_{i} \times H_{i}\right)}{\sum_{i=1}^{N} S_{i}}$

Building heterogeneity $=H_{\text {area }} / H_{\text {bldg }}(1=$ perfectly homogeneous $)$

Building density $=\frac{\sum_{i=1}^{N} S_{i}}{\text { sampling area }}(1=$ entirely covered by buildings, $0=$ open space $)$

where, $N$ is number of buildings in the sampling area, $H_{i}$ and $S_{i}$ are height and area of the $i^{\text {th }}$ building, respectively. Sampling area is defined as the area of the rectangle covering the sampling area, as shown in Fig. 1 . We note that a simple arithmetic mean of $H_{b l d g}$ can be significantly lowered when a sampling area consists of one very large isolated skyscraper and a 
large number of small short buildings such as Site 2 and Site 3 . Thus, we use $H_{\text {area }}$, which is defined as the building surface area-weighted average height (Eq. 2). Consequently, the dimensionless ratio of $H_{\text {area }}$ to $H_{\text {bldg }}$ represents the building heterogeneity; this has a value of 1 for perfectly homogeneous and higher values for more heterogeneous building morphology. Sitel and Site5 have the most homogeneous built environments (heterogeneity of 1.16 and 1.09, respectively) but are very different: Sitel has all tall buildings ( $>40 \mathrm{~m}$ height street canyon) and Site 5 has all small one-story buildings (lowest building canopy of $6 \mathrm{~m}$ ). Tall buildings on one side and small ones on the other side gave Site 4 an intermediate homogeneity of 1.39. Site2 and Site3 were the most heterogeneous (2.01 and 2.21, respectively). All of these quantitative parameters can be compared directly with our observed UFP concentrations to find the direct effects of built environments. 
Table 4. Surface micrometeorological conditions observed for sampling periods. Values in parentheses of the temperature and wind speed columns represent standard deviations.

\begin{tabular}{|c|c|c|c|c|c|c|c|c|c|c|}
\hline \multirow[b]{2}{*}{ Date } & \multicolumn{5}{|c|}{ Morning } & \multicolumn{5}{|c|}{ Afternoon } \\
\hline & Temp. $\left({ }^{\circ} \mathrm{C}\right)$ & $\begin{array}{c}{ }^{\mathrm{a}} \text { Wind } \\
\text { speed } \mathrm{m} / \mathrm{s}\end{array}$ & $\begin{array}{c}\boldsymbol{u}_{*} \\
\mathrm{~m} / \mathrm{s}\end{array}$ & $\begin{array}{c}\sigma_{w} \\
\mathrm{~m} / \mathrm{s}\end{array}$ & $\begin{array}{l}\text { TKE } \\
\mathrm{m}^{2} \mathrm{~s}^{-2}\end{array}$ & Temp. $\left({ }^{\circ} \mathrm{C}\right)$ & $\begin{array}{c}{ }^{\mathrm{a}} \text { Wind } \\
\text { speed } \mathrm{m} / \mathrm{s}\end{array}$ & $\begin{array}{c}u_{*} \\
\mathrm{~m} / \mathrm{s}\end{array}$ & $\begin{array}{c}\sigma_{w} \\
\mathrm{~m} / \mathrm{s}\end{array}$ & $\begin{array}{l}\text { TKE } \\
\mathrm{m}^{2} \mathrm{~s}^{-2}\end{array}$ \\
\hline & \multicolumn{10}{|c|}{ Sitel (Street Canyon) } \\
\hline $7 / 1$ & $25.9( \pm 1.7)$ & $1.0( \pm 0.2)$ & 0.23 & 0.37 & 0.47 & $32.2( \pm 2.1)$ & $1.1( \pm 0.3)$ & 0.23 & 0.40 & 0.46 \\
\hline $7 / 2$ & $26.1( \pm 1.4)$ & $1.2( \pm 0.3)$ & 0.27 & 0.40 & 0.61 & $23.5( \pm 1.2)$ & $1.7( \pm 0.3)$ & 0.29 & 0.52 & 1.02 \\
\hline $7 / 3$ & $23.0( \pm 1.3)$ & $1.2( \pm 0.1)$ & 0.17 & 0.35 & 0.47 & $22.5( \pm 1.0)$ & $1.7( \pm 0.2)$ & 0.36 & 0.57 & 0.97 \\
\hline $7 / 5$ & $20.6( \pm 1.4)$ & $0.9( \pm 0.2)$ & 0.19 & 0.30 & 0.47 & $24.0( \pm 0.6)$ & $1.6( \pm 0.2)$ & 0.15 & 0.48 & 1.21 \\
\hline \multirow[t]{2}{*}{$11 / 13$} & $24.2( \pm 0.4)$ & $0.8( \pm 0.2)$ & 0.20 & 0.27 & 0.18 & $29.9( \pm 0.6)$ & $0.5( \pm 0.1)$ & 0.12 & 0.19 & 0.08 \\
\hline & \multicolumn{10}{|c|}{ Site2 (Isolated skyscraper with low traffic rates) } \\
\hline $9 / 24$ & $26.6( \pm 0.4)$ & $0.8( \pm 0.2)$ & 0.15 & 0.24 & 0.23 & $28.3( \pm 0.2)$ & $2.1( \pm 0.6)$ & 0.72 & 0.73 & 1.90 \\
\hline \multirow[t]{2}{*}{$9 / 25$} & $21.7( \pm 0.5)$ & $1.9( \pm 0.6)$ & 0.88 & 0.97 & 1.83 & $24.9( \pm 0.4)$ & $3.3( \pm 0.4)$ & 0.48 & 0.59 & 1.84 \\
\hline & \multicolumn{10}{|c|}{ Site 3 (Isolated skyscrapers with high traffic rates) } \\
\hline $10 / 7$ & $22.8( \pm 0.5)$ & $1.4( \pm 0.4)$ & 0.13 & 0.41 & 0.77 & $27.8( \pm 0.7)$ & $2.6( \pm 0.5)$ & 0.40 & 0.68 & 2.11 \\
\hline $10 / 14$ & $17.9( \pm 1.4)$ & $0.7( \pm 0.1)$ & 0.35 & 0.38 & 0.31 & $28.6( \pm 0.4)$ & $1.9( \pm 0.3)$ & 0.42 & 0.61 & 1.26 \\
\hline \multirow[t]{2}{*}{$11 / 18$} & $15.4( \pm 0.4)$ & $0.9( \pm 0.2)$ & 0.23 & 0.36 & 0.39 & $20.2( \pm 0.4)$ & $2.6( \pm 0.3)$ & 0.27 & 0.70 & 1.60 \\
\hline & \multicolumn{10}{|c|}{ Site4 (One-side medium height buildings) } \\
\hline $11 / 1$ & $17.2( \pm 1.7)$ & $1.2( \pm 0.4)$ & 0.16 & 0.39 & 0.54 & $29.1( \pm 0.4)$ & $0.9( \pm 0.2)$ & 0.43 & 0.56 & 0.51 \\
\hline $11 / 6$ & $15.1( \pm 1.4)$ & $0.9( \pm 0.1)$ & 0.20 & 0.37 & 0.35 & $26.3( \pm 0.3)$ & $0.6( \pm 0.2)$ & 0.27 & 0.27 & 0.25 \\
\hline \multirow[t]{2}{*}{$11 / 20$} & $16.0( \pm 0.3)$ & $0.5( \pm 0.1)$ & 0.19 & 0.23 & 0.17 & $19.1( \pm 0.2)$ & $1.7( \pm 0.3)$ & 0.13 & 0.38 & 0.74 \\
\hline & \multicolumn{10}{|c|}{ Site5 (Low and Flat) } \\
\hline $8 / 6$ & & & & & & $29.4( \pm 0.6)$ & $1.5( \pm 0.1)$ & 0.45 & 0.63 & 1.07 \\
\hline $9 / 17$ & $21.4( \pm 0.5)$ & $0.7( \pm 0.1)$ & 0.10 & 0.26 & 0.24 & $30.3( \pm 1.1)$ & $1.1( \pm 0.2)$ & 0.26 & 0.40 & 0.47 \\
\hline $9 / 18$ & $20.0( \pm 0.6)$ & $0.6( \pm 0.1)$ & 0.18 & 0.27 & 0.23 & $29.0( \pm 0.8)$ & $1.0( \pm 0.2)$ & 0.23 & 0.39 & 0.41 \\
\hline
\end{tabular}

a. Wind speeds represent the ground level values obtained with sonic anemometer

measurements. Thus wind direction is strongly influenced by localized built environment, and not shown in this table. Prevailing wind direction over the urban canopy obtained from nearby weather station is presented in Table S1 in SI 3. 


\section{Results and Discussions}

\subsection{General Features of UFP concentrations}

To compare the representative levels of pollutants due to roadway emissions in various built environments, concentrations obtained from mobile measurements within each sampling area were averaged. Due to significant differences in meteorology between early morning and afternoon (e.g., boundary layer depth, vertical mixing capacity, prevailing winds, and possibly secondary formation of nucleation mode particles), the morning and afternoon session results are analyzed and discussed separately.

Figure 3 shows the daily mean UFP concentrations ([UFP] hereinafter) for each site. In general, [UFP] were higher in the morning than in the afternoon due to lower boundary layer heights with less turbulence, which limit vertical dispersion of emissions and increase pollutant residence time in the surface layer. Exceptions were Site5, Site 2 on 5 September, and Site1 on 5 July, which showed higher concentrations in the afternoon. This cannot be explained by either emissions or dispersion because traffic rates were comparable to morning sessions and the surface atmosphere was more turbulent with a deeper boundary layer in the afternoon. The estimated boundary layer heights from vertical temperature profiles observed at Los Angeles International Airport (18 km southwest from Sitel) were at least two times higher in the afternoon than morning sampling periods on these days: $236 \mathrm{~m}$ vs. $798 \mathrm{~m}$ on 9/5/2013; $174 \mathrm{~m}$ vs. $361 \mathrm{~m}$ on 9/17/2013; and $298 \mathrm{~m}$ vs. $486 \mathrm{~m}$ on 9/18/2013 (data on 7/5/2013 are not available). 

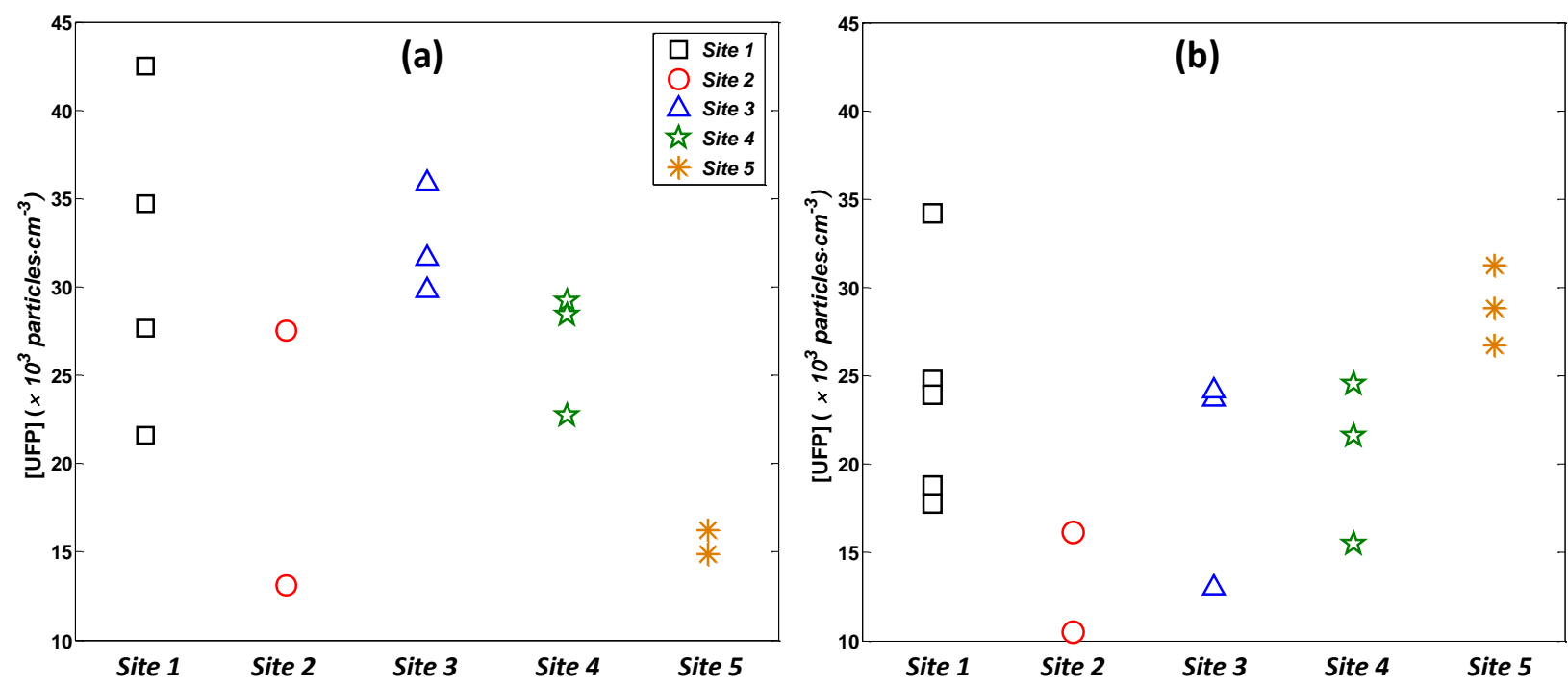

Figure 3. Daily averaged [UFP] in the (a) morning and (b) afternoon sampling sessions at each site.

We hypothesize that enhanced afternoon concentrations were caused by photochemical secondary production of UFP (Hu et al., 2012; Ning et al., 2007). The interesting feature is that the afternoon elevation in the transient high-spikes-removed [UFP] (see SI 5 for details) was observed only when the morning [UFP] were less than $2 \times 10^{4}$ particles $\cdot \mathrm{cm}^{-3}$. On the other days, morning and afternoon concentrations were linearly related to one another (Fig. S8). In the morning of 5 July at Site1, however, $\mathrm{PM}_{2.5}$ values were extraordinarily high (above the upper limit of DustTrak, $>1 \mathrm{mg} / \mathrm{m}^{3}$ ), presumably due to Independence Day fireworks on the evening of 4 July. Thus, lower [UFP] in the morning could be due to lower traffic (24\% lower) and/or an increased coagulational sink for fresh UFP from the dramatically increased $\mathrm{PM}_{2.5}$. Sitel, the street canyon site in DTLA, had the highest [UFP] in both morning and afternoon, likely due to limited mixing with upper ambient air. Site1 has a fairly homogeneous high building canopy and high simple aspect ratio, $A_{r}=1.7$ (defined as the ratio of $H_{\text {area }}$ to the mean street width, Table 2).

Site5 had the lowest [UFP] in the morning presumably due to its built environment (the lowest $H_{\text {area }}$ and $A_{r}$, Table 2), which less inhibits vertical mixing. Site2 also had low [UFP] 
compared to the other sites, even though the simple $A_{r}$ at this site is highest $\left(A_{r}=1.9\right)$. This can be explained by relatively low traffic rates at this site, combined with a negligible number of vehicles in queues during red lights. We also note that the simple $A_{r}$ does not account for open spaces (e.g. the gaps between buildings or large parking lots). The high $A_{r}$ at Site 2 derives from two tall isolated skyscrapers but this site also has vast open parking areas (Fig. S2), as shown by the minimal number of buildings in the selected area (Table 2). Morning [UFP] at Site3 were comparable to Site 1 but sharply decreased in the afternoon, reaching levels similar to Site 4 and lower than Site1. The elevated concentrations in the morning at Site3 were likely due to both the heavy traffic flows and density (Table 3). However, given that traffic rate and density at Site3 were similar between morning and afternoon sessions and higher than those at Site1 and Site4, lowered afternoon [UFP] compared to Site1 and Site4 cannot be readily explained. Consequently, these observations strongly suggest that [UFP] for each site are controlled by different factors depending on meteorological and built-environmental conditions. Quantitative discussions concerning factors controlling the UFP levels in various environments are presented in Section 4.3 .

\subsection{Elevated emissions at the intersections}

One of the objectives of this field study was to investigate variations in [UFP] from roadway emissions in the close vicinity of pedestrian walkways (thus, closely reflecting pedestrian exposure) in various micro-built environments. In this respect, we present general quantitative impacts of vehicle acceleration at intersections. Figure 4 shows the session mean [UFP] at intersection corners (measured with stationary DiSCminis) vs. the average for the whole sampling area (measured with the MMP). The intersection averages were consistently higher than the whole sampling area average in both morning and afternoon sessions for all sites except Site3 afternoon sessions. In the morning, [UFP] at the intersections was higher than the 
sampling area average by $24 \%, 10 \%, 5 \%, 11 \%$ and $55 \%$ at Site 1, 2, 3, 4 and 5, respectively; in the afternoon, intersections corners were higher by $36 \%, 31 \%,-14 \%, 18 \%$ and $31 \%$, respectively. Traffic at Site3 was concentrated on Vermont Ave. and, due to a long queue that covered the entire sampling blocks, acceleration events were limited and occurred over the whole sampling section of Vermont Ave., likely causing less significant intersection impacts.
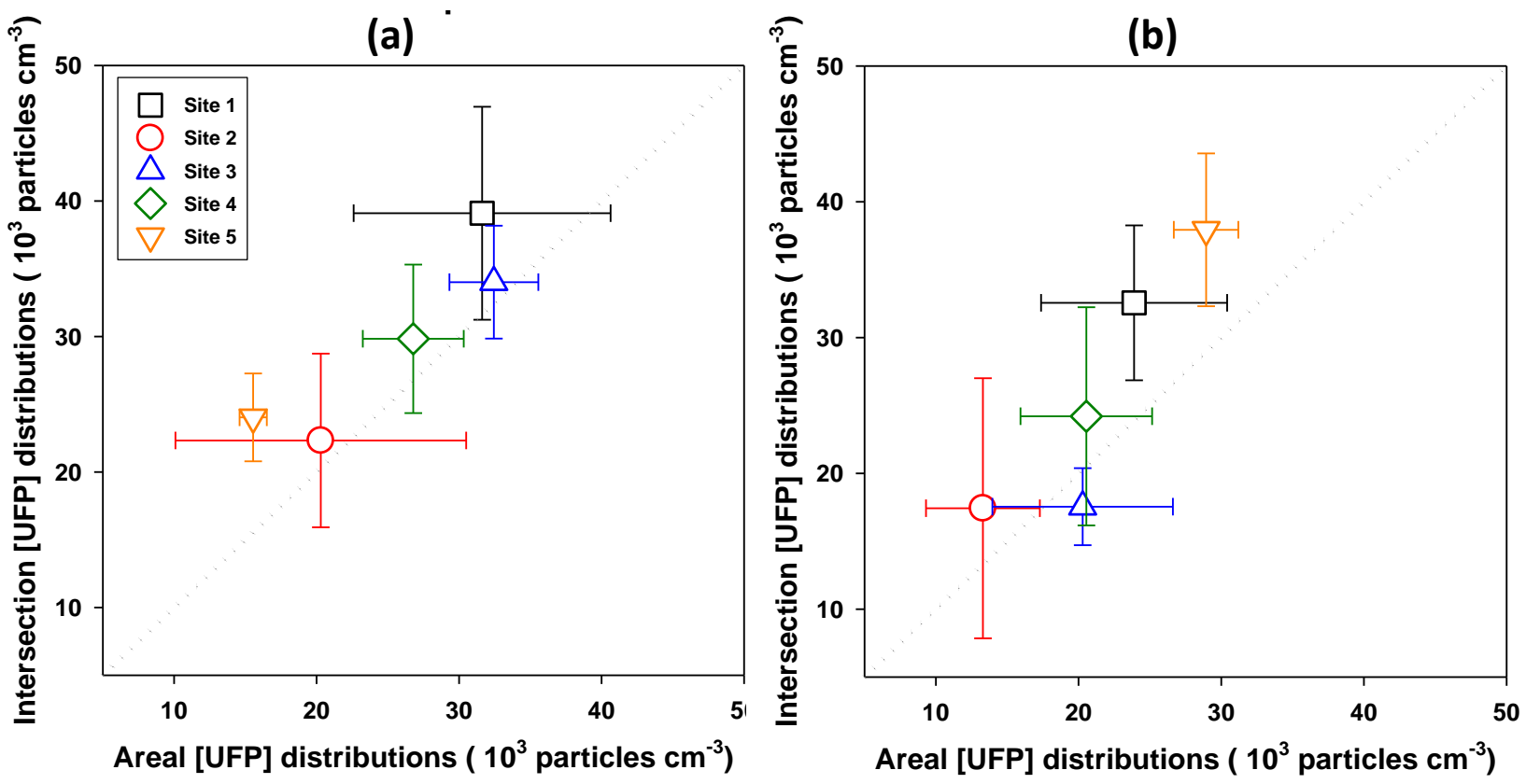

Figure 4. The mean intersection vs. area-wide [UFP] distributions (a) in the morning and (b) afternoon sampling sessions at each site. Vertical bars denote standard deviations.

Consistently higher [UFP] at the corners of intersections provides clear evidence that acceleration of vehicles at intersections increases pedestrian exposure to UFP. This is consistent with the argument in Klems et al.(2010) that the dominant period of transient spikes in UFP time-series matches traffic-light cycles. Although Klems et al.(2010) addressed only occurrences and periods of spikes from the intersection accelerations, we additionally observed that the spikeremoved baseline levels obtained with the same method in Choi et al. (2013) (and described briefly in SI 5) were higher also at intersection corners compared to the values over the sampling 
area: $29 / 33 \%, 15 / 38 \%, 2 / 3 \%, 7 / 18 \%$, and $61 / 27 \%$ for Sites $1,2,3,4$, and 5 in the

morning/afternoon, respectively (Fig. S9). This implies, perhaps unsurprisingly, that higher emissions from vehicle accelerations at intersections are quickly mixed with ambient air and, at steady-state, result in persistently higher [UFP] in the intersection areas.

Given that the MMP route includes intersection areas (Fig. 1) and the peak concentrations due to acceleration do not necessarily appear exactly at the corners (they can instead appear before and/or after intersections) (Ranasinghe et al., 2015), the concentration difference at intersection vs. over the sampling area can be higher than the values presented above. More complete analyses for the intersection impacts (including the locations and shapes of intersection peaks) will be presented separately.

\subsection{Factors controlling near-roadway UFP concentrations}

\subsubsection{Calm morning conditions}

Most morning sampling periods were calm, and meteorological variations between sites were not sufficient to explain the wide [UFP] variations among sites (Fig. SI 7). Traffic differences were noticeable between sites, but day-to-day variations at a single site were relatively insignificant. It appears that, in general, higher traffic rates led to higher levels of UFP, except at the two sites with extreme built-environments: the street canyon (Sitel) and the low, flat canopy (Site5). The homogeneous high building canopy in the street canyon had higher [UFP] compared to observed traffic flow rates, and the opposite was true for the homogeneous and lowest building canopy (Fig. 5a). 

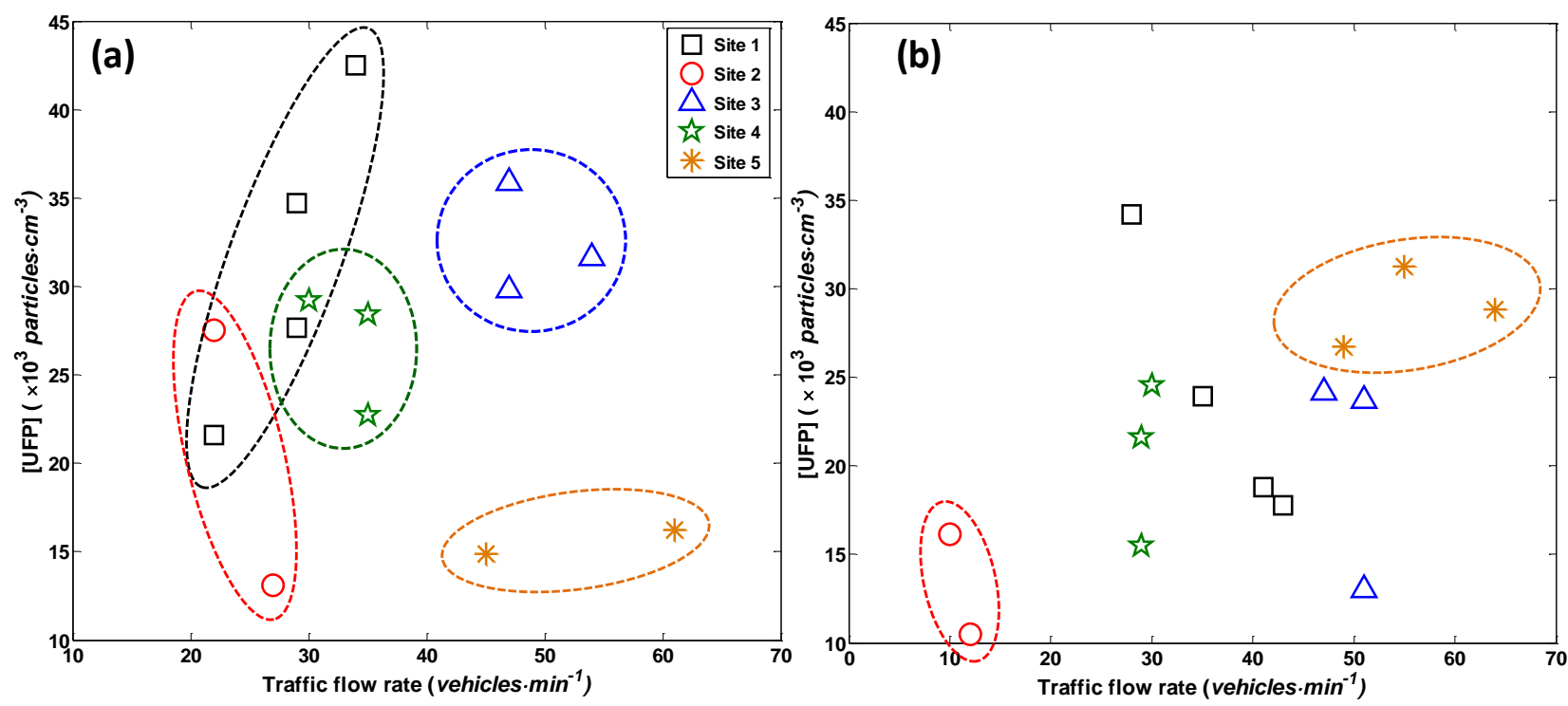

Figure 5. Daily [UFP] as a function of traffic flow rates (vehicles $\cdot \mathrm{min}^{-1}$ ) in the(a) morning and (b) afternoon sampling sessions. Ovals show a group of sampling site.

A noticeable positive correlation was found between [UFP] and building area-weighted building height $H_{\text {area }}$, particularly in the morning (Fig. S10 in SI. 6). Site 1 and Site 2 have similar $H_{\text {area }}$ values of around $40 \mathrm{~m}$, however, the high $H_{\text {area }}$ at Site 2 results from few very tall buildings $(\sim 130 \mathrm{~m})$ on a site with many large open parking lots around the intersection (Table2 and Fig. S2a), while Site1 is largely surrounded by $\sim 40 \mathrm{~m}$ buildings. To better capture the different builtenvironmental characteristics, a block-scale areal aspect ratio $\left(A r_{\text {area }}\right)$ was developed (Eq. 5):

$$
A r_{\text {area }}=\frac{H_{\text {area }}}{L_{\text {diag }} \times\left(1-\sum S_{\text {bldg }} / A_{\text {site }}\right)}=\frac{H_{\text {area }}}{L_{\text {diag }} \times\left(A_{\text {open }} / A_{\text {site }}\right)}=\frac{H_{\text {area }}}{L_{\text {open }}}
$$

where $\Sigma S_{\text {bldg }}$ is the sum of the building ground areas, $A_{\text {site }}$ is the area of the sampling site, $L_{\text {diag }}$ is the diagonal block length, and $L_{\text {open }}$ and $A_{\text {open }}$ are the length scale and area of open space, respectively. 


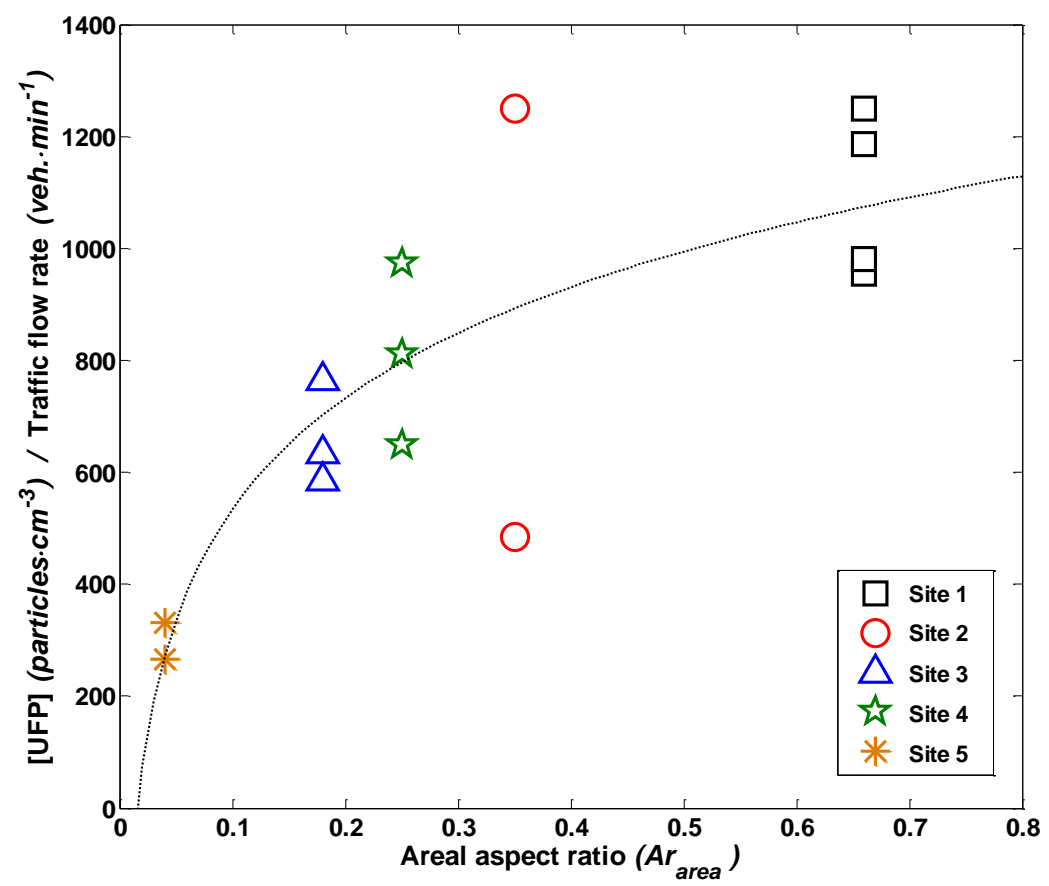

Figure 6. Relationship between area aspect ratio $\left(A r_{\text {area }}\right)$ and [UFP] normalized to traffic flow rates in the morning $\left(R^{2}=0.67\right)$.

The traffic-corrected [UFP], which is defined simply as observed [UFP] divided by observed traffic flow rate, showed a strong relationship with $A r_{\text {area }}$ (Fig. 6 and Eq. 6):

$$
\frac{[U F P]}{\text { Traffic flow rate }}=286 \times \log \left(A r_{\text {area }}\right)+1193 \quad\left(R^{2}=0.67\right)
$$

Due to a log form of the best fit curve, [UFP] increase sharply with $A r_{\text {area }}$ in a low $A r_{\text {area }}$ regime, but in a high $A r_{\text {area }}$ regime, the slope of [UFP] elevation with $A r_{\text {area }}$ is dampened. The log form of the best fit implies that once the aspect ratio is above a critical level, recirculation cells form in the lower part of building canopy (Liu et al., 2004). Once the in-canopy recirculation cells are a dominant feature, additional increases in aspect ratio have a weaker effect on ground-level vehicular pollutants because recirculation cells separate ground-level in-canopy air from upper ambient air. More details about air flow impacts on spatial distributions of pollutants will be presented in a separate study (Ranasinghe et al., 2015). Consequently, our results suggest that 
built environments, particularly the areal aspect ratio $\left(A r_{\text {area }}\right)$ and traffic conditions, determine the spatial patterns of UFP levels under calm morning conditions.

\subsubsection{Unstable afternoon conditions}

In the afternoon, the areal aspect ratio does not explain the afternoon [UFP] between sites as well as it does for morning distributions (Fig. S10). This is not surprising given an increasing meteorological influence due to more diverse meteorology between sites/days in the afternoon, such as deeper boundary layer depth and stronger turbulence intensities (Choi et al., 2011; Hussein et al., 2006; Seibert et al., 2000), as well as the additional possible UFP source of photochemical secondary production (Hu et al., 2012; Ning et al., 2007).

In the afternoon, vertical fluctuations of winds $\left(\sigma_{w}\right)$ are the strongest factor in determining UFP levels, as shown by the straightforward relationships between [UFP] and $\sigma_{w}\left(\mathrm{R}^{2}=0.43\right.$, Fig. 7). As the surface atmosphere becomes more turbulent (higher $\sigma_{w}$ ), UFP levels decrease due to stronger atmospheric dispersion. The effect of $\sigma_{w}$ on [UFP] becomes more evident when [UFP] are corrected by traffic flow rate; $R^{2}$ values increase up to 0.83 (Fig. $7 b$ ). Note that two data points obtained from Site 2 clearly departed from the trend and thus were excluded from the curve fitting analyses. Site 2 has very infrequent traffic with traffic flow rates of only $1 / 3$ to $1 / 5$ that of other sites (Table 2). Relatively high [UFP] despite minimal vehicular emissions at this site are likely caused by an influx from nearby busy streets combined with a contribution from secondary production (Brines et al., 2015). This implies that an understanding of horizontal wind fields is required to understand the heterogeneous spatial distributions of pollutants, particularly on streets with little pollution of their own. 

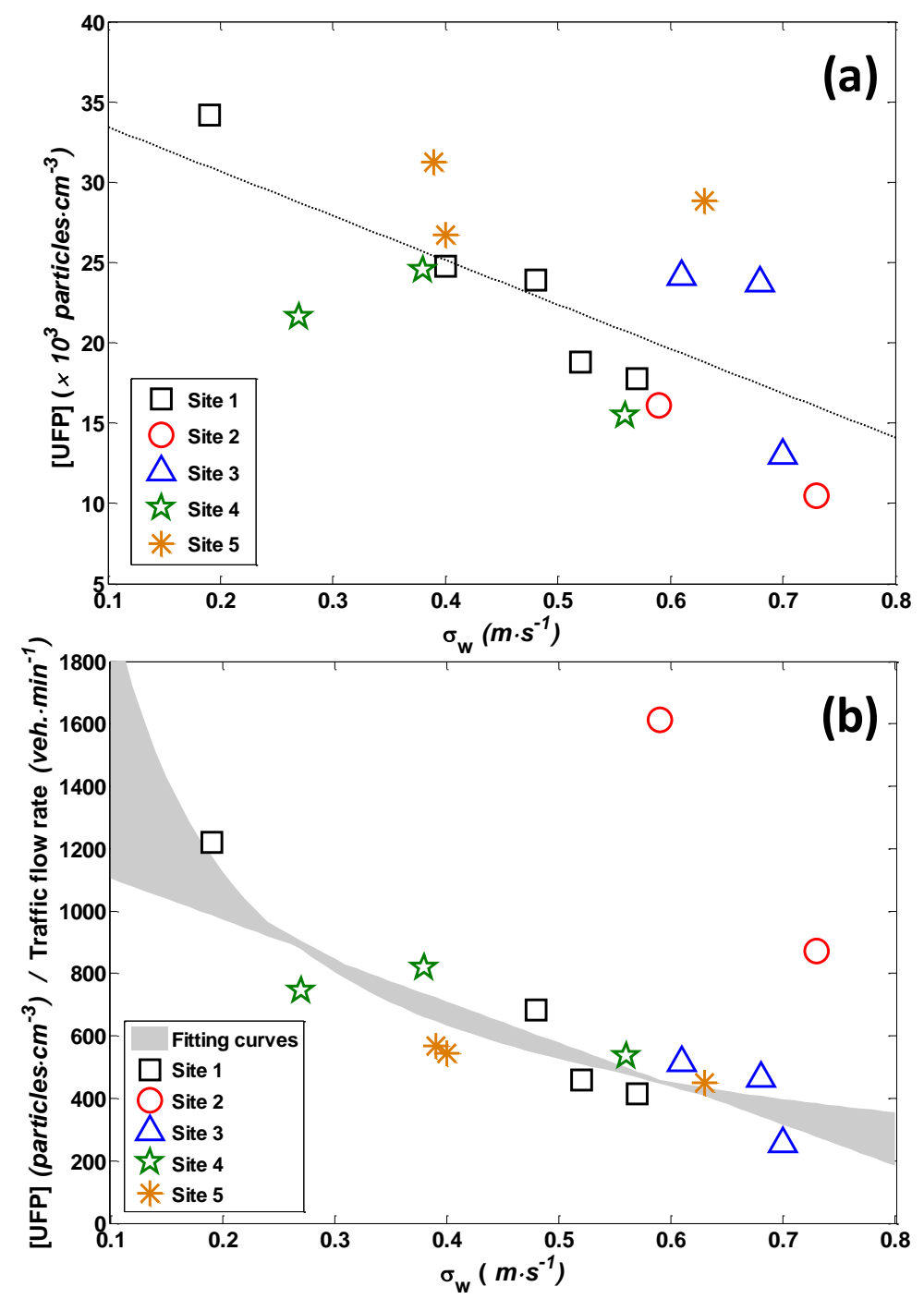

Figure 7. Relationship between [UFP] and $\sigma_{w}$ for afternoon sessions. (a) [UFP] vs $\sigma_{w}$ and (b) [UFP] normalized by observed traffic flows vs. $\sigma_{w}$. The gray area represents the range of best fit curves as described in the text. The values for Site 2 are excepted from the analysis due to very low traffic counts on the street and subsequent likely contributions from nearby streets and other sources (see text).

There is not an obvious theoretical basis from which to derive a quantitative relationship between $\sigma_{w}$ and traffic normalized [UFP], and our data do not span a large enough range to suggest the best form. Thus, several types of simple curve fits were applied: linear, exponential, logarithmic, and power (Eq. 7). The linear form resulted in slightly lower $\mathrm{R}^{2}$ value compared to others. Although the fitted values disperse widely at the both ends, all fits showed a good 
agreement within observed $\sigma_{w}$ range; the shaded area in Fig. $7 \mathrm{~b}$ shows the maximum and minimum values of the curve fits.

$$
\begin{array}{rlr}
\frac{P N C}{\text { Traffic flow rate }} & =-1315 \cdot \sigma_{w}+1236 & \left(R^{2}=0.74\right) \\
& =1645 \cdot \exp \left(-2.21 \cdot \sigma_{w}\right) & \left(R^{2}=0.80\right) \\
& =-563 \cdot \log \left(0.76 \cdot \sigma_{w}\right) & \left(R^{2}=0.81\right) \\
& =296 \cdot \sigma_{w}^{-0.83} & \left(R^{2}=0.83\right)
\end{array}
$$

The strong relationships between traffic-normalized [UFP] and $\sigma_{w}$ emphasize the role of surface micrometeorology in determining afternoon pollutant levels. However, we hypothesize that built environments also affect pollutant distributions indirectly by altering the strength of turbulence intensities. To support this hypothesis, the comparisons between heterogeneity of building morphology for each site and observed surface turbulence parameters are shown in Fig.

8.
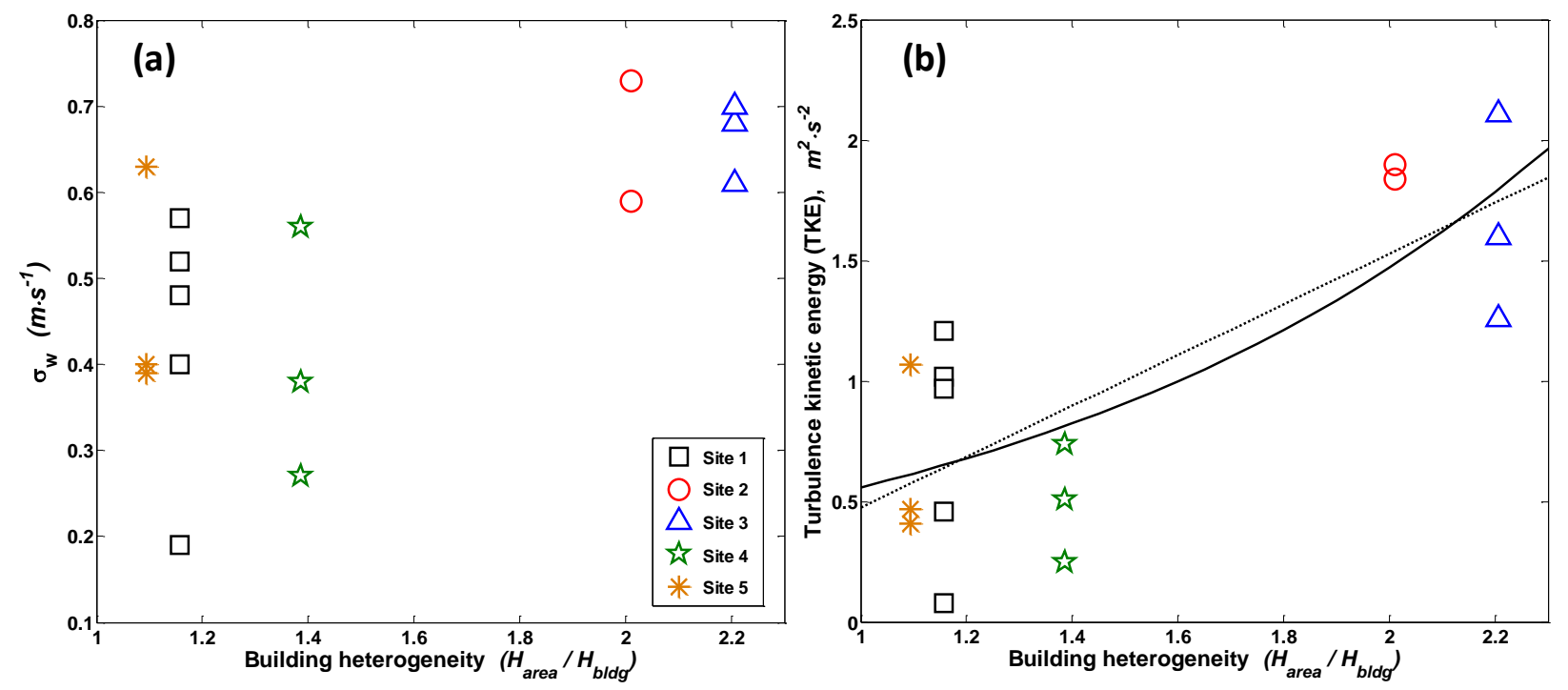

Figure 8. Afternoon relationships between building heterogeneity vs. turbulence intensities: (a) vertical fluctuation of winds and (b) total turbulence kinetic energy (TKE) defined as $T K E=1 / 2 \sqrt{\sigma_{u}{ }^{2}+\sigma_{v}{ }^{2}+\sigma_{w}{ }^{2}}$. Dotted and solid lines in (b) represent the best fits in linear $\left(R^{2}=0.60\right)$ and exponential $\left(R^{2}=0.60\right)$ forms, respectively, for illustration of the increase trends of TKE with building heterogeneity. 
The fluctuations of vertical winds that showed the strongest relationships with the afternoon [UFP] appear to be somewhat related to building heterogeneity (Fig. 8a). However, the daily variations of $\sigma_{w}$ for each site are so large compared to the magnitude of the observed range that the relationships are not so strong. On the other hand, it is clear that the most heterogeneous sites, Site 2 and Site 3 , had consistently stronger $\sigma_{w}$ than other more homogeneous sites. Indeed, the surface level turbulence kinetic energy for each site sharply increased with building heterogeneity (Fig. 8b). This relationship implies that a heterogeneous building configuration enhances surface level turbulence, intensifying atmospheric dispersive capacity and reducing surface pollutant levels under unstable daytime conditions.

\section{Implications for urban planners and traffic managers}

Our research findings have implications for urban planning, traffic management policies and air pollution exposure of pedestrians and vehicle occupants in urban centers. Broadly, our data provide quantitative insights into how the built environment and traffic flows influence pedestrian exposure to vehicle pollution, and offer urban planners and traffic managers strategies to reduce street level pollutant concentrations.

Table 5 summarizes built environment and traffic management design characteristics at the block scale that influence near-roadway exposures to vehicle pollution. Our findings that lower traffic flows and fewer stops reduce near-roadway pollution are consistent with earlier studies and enlightened traffic management policies. In addition to the obvious dependence on traffic volumes, different built environment characteristics are important at different atmospheric stability/times of the day. For calm mornings, the area aspect ratio $\left(A r_{\text {area }}\right)$ was an important factor in controlling the block-scale vehicular pollutant concentrations. Higher values of $A r_{\text {area }}$, correspond to more building volume and less open space, and limited mixing with ambient air 
above. On the other hand, turbulence intensities, represented by $\sigma_{w}$, played a major role in dispersing vehicular emissions in the afternoon. The built environment affects surface turbulence intensities, and thus plays an indirect role in controlling block-scale [UFP]. An isolated tall building surrounded by open space or short buildings is likely help to reduce the levels of vehicular pollution by increasing surface level turbulence intensities. Thus, urban planning focused on decreasing $A r_{\text {area }}$ and increasing heterogeneity of building distributions is expected to substantially improve near-roadway air quality and reduce pedestrian exposure to vehicular emissions.

Table 5. Summary for planners: Built environment and traffic management design characteristics that influence near-roadway exposures to vehicular pollution.

\begin{tabular}{|c|c|c|c|}
\hline Management & Suggested Direction & $\begin{array}{c}\text { Approx. Size of } \\
\text { Effect }\end{array}$ & $\begin{array}{l}\text { Atmospheric } \\
\text { Conditions\& Notes }\end{array}$ \\
\hline $\begin{array}{l}\text { Areal aspect ratio }\left(A_{\text {area }}\right) \\
A_{\text {area }} \text { combines building } \\
\text { area-weighted height, } \\
\text { building footprint, and the } \\
\text { amount of open space. }\end{array}$ & $\begin{array}{l}\text { Lower building volumes } \\
\text { and more open space } \\
\text { result in lower pollutant } \\
\text { concentrations. }\end{array}$ & $\begin{array}{l}\text { Up to } \\
\text { approximately a } \\
\text { factor of three. }\end{array}$ & $\begin{array}{l}\text { Important under calm } \\
\text { conditions (in the } \\
\text { mornings at our sites). } \\
\text { Not critical when the } \\
\text { atmosphere is unstable. }\end{array}$ \\
\hline Building Heterogeneity & $\begin{array}{l}\text { Isolated tall buildings } \\
\text { result in lower } \\
\text { concentrations than } \\
\text { homogeneous shorter or } \\
\text { higher buildings with } \\
\text { similar volume. }\end{array}$ & $\begin{array}{l}\text { Up to } \\
\text { approximately a } \\
\text { factor of two. }\end{array}$ & $\begin{array}{l}\text { Important under unstable } \\
\text { conditions with moderate } \\
\text { winds (afternoons at our } \\
\text { sites). Not critical when } \\
\text { the atmosphere is stable. }\end{array}$ \\
\hline Traffic flow & $\begin{array}{l}\text { Lower traffic flow is } \\
\text { better, controlling for } \\
\text { fleet mix. }\end{array}$ & $\begin{array}{l}\text { At a given } \\
\text { location, } \\
\text { concentrations are } \\
\text { roughly } \\
\text { proportional to } \\
\text { traffic flow. }\end{array}$ & \\
\hline Traffic Management & $\begin{array}{l}\text { Fewer stops and smaller } \\
\text { queues reduce } \\
\text { emissions and elevated } \\
\text { concentrations around } \\
\text { intersections }\end{array}$ & $\begin{array}{l}\text { Cannot estimate } \\
\text { from our data }\end{array}$ & $\begin{array}{l}\text { Concentrations depend on } \\
\text { emissions, micro-scale } \\
\text { turbulence, dispersion, } \\
\text { transport from nearby } \\
\text { streets, and other factors }\end{array}$ \\
\hline
\end{tabular}




\section{Acknowledgements}

The authors gratefully acknowledge support for this study by the California Air Resources Board, Contract No. 12-308 and U.S. National Science Foundation, Contract No. CNS-1111971001. The first author was partially funded by Korean Ministry of Environment through "Climate Change Correspondence Program". The mobile monitoring platform measurements were made possible with the generous assistance of our colleagues Kathleen Kozawa and Steve Mara. The authors also appreciate Prof. A. Venkatram, Mr. Schulte, and Dr. S. Tan at the University of California, Riverside for the sonic anemometer data. The views and opinions in this study are those of the authors and do not reflect the official views of the CARB.

\section{References}

Bau, S., Zimmermann, B., Payet, R., Witschger, O., 2015. A laboratory study of the performance of the handheld diffusion size classifier (DiSCmini) for various aerosols in the 15-400 $\mathrm{nm}$ range. Environmental Science: Processes \& Impacts, Advance Article, DOI:10.1039/c1034em00491d.

Behrentz, E., Sabin, L.D., Winer, A.M., Fitz, D.R., Pankratz, D.V., Colome, S.D., Fruin, S.A., 2005. Relative importance of school bus-related microenvironments to children's pollutant exposure. J. Air Waste Manage. Assoc. 55, 1418-1430.

Boarnet, M.G., Houston, D., Edwards, R., Princevac, M., Ferguson, G., Pan, H.S., Bartolome, C., 2011. Fine particulate concentrations on sidewalks in five Southern California cities. Atmos. Environ. 45, 4025-4033.

Boogaard, H., Kos, G.P.A., Weijers, E.P., Janssen, N.A.H., Fischer, P.H., van der Zee, S.C., de Hartog, J.J., Hoek, G., 2011. Contrast in air pollution components between major streets and background locations: Particulate matter mass, black carbon, elemental composition, nitrogen oxide and ultrafine particle number. Atmos. Environ. 45, 650-658.

Brines, M., Dall'Osto, M., Beddows, D.C.S., Harrison, R.M., Gomez-Moreno, F., Nunez, L., Artinano, B., Costabile, F., Gobbi, G.P., Salimi, F., Morawska, L., Sioutas, C., Querol, X., 2015. Traffic and nucleation events as main sources of ultrafine particles in high-insolation developed world cities. Atmospheric Chemistry and Physics 15, 5929-5945.

Brugge, D., Durant, J.L., Rioux, C., 2007. Near-highway pollutants in motor vehicle exhaust: A review of epidemiologic evidence of cardiac and pulmonary health risks. Environ. Health 6, 12.

Buonanno, G., Fuoco, F.C., Stabile, L., 2011. Influential parameters on particle exposure of pedestrians in urban microenvironments. Atmos. Environ. 45, 1434-1443.

Capaldo, K., Pandis, S., 2001. Lifetimes of ultrafine diesel aerosol, Report for the University of Minnesota and the coordinating research council under the E-43 project diesel aerosol sampling methodology. Carnegie Mellon University, Pittsburgh, PA.

Choi, W., Faloona, I.C., McKay, M., Goldstein, A.H., Baker, B., 2011. Estimating the atmospheric boundary layer height over sloped, forested terrain from surface spectral analysis during BEARPEX. Atmospheric Chemistry and Physics 11, 6837-6853. 
Choi, W., He, M., Barbesant, V., Kozawa, K.H., Mara, S., Winer, A.M., Paulson, S.E., 2012. Prevalence of wide area impacts downwind freeways under pre-sunrise stable atmospheric conditions. Atmospheric Environment 62, 318-327.

Choi, W., Hu, S.S., He, M., Kozawa, K.H., Mara, S., Winer, A.M., Paulson, S.E., 2013. Neighborhood-scale air quality impacts of emissions from motor vehicles and aircraft. Atmospheric Environment 80, 310-321.

Fruin, S.A., Winer, A.M., Rodes, C.E., 2004. Black carbon concentrations in California vehicles and estimation of in-vehicle diesel exhaust particulate matter exposures. Atmos. Environ. 38, 41234133.

Haughey, R., Sherriff, R., 2010. Challenges and Policy Options for Creating and Preserving Affordable Housing near Transit and Other Location-efficient Areas., Center for Housing Policy.

Hoek, G., Brunekreef, B., Goldbohm, S., Fischer, P., van den Brandt, P.A., 2002. Association between mortality and indicators of traffic-related air pollution in the Netherlands: a cohort study. Lancet 360, 1203-1209.

Hu, S., Paulson, S.E., Fruin, S., Kozawa, K., Mara, S., Winer, A.M., 2012. Observation of elevated air pollutant concentrations in a residential neighborhood of Los Angeles California using a mobile platform. Atmospheric Environment 51, 311-319.

Hussein, T., Karppinen, A., Kukkonen, J., Harkonen, J., Aalto, P.P., Hameri, K., Kerminen, V.M., Kulmala, M., 2006. Meteorological dependence of size-fractionated number concentrations of urban aerosol particles. Atmospheric Environment 40, 1427-1440.

Janssen, N.A.H., Brunekreef, B., van Vliet, P., Aarts, F., Meliefste, K., Harssema, H., Fischer, P., 2003. The relationship between air pollution from heavy traffic and allergic sensitization, bronchial hyperresponsiveness, and respiratory symptoms in Dutch schoolchildren. Environ. Health Perspect. 111, 1512-1518.

Klems, J.P., Pennington, M.R., Zordan, C.A., Johnston, M.V., 2010. Ultrafine Particles Near a Roadway Intersection: Origin and Apportionment of Fast Changes in Concentration. Environmental Science \& Technology 44, 7903-7907.

Kozawa, K.H., Fruin, S.A., Winer, A.M., 2009. Near-road air pollution impacts of goods movement in communities adjacent to the Ports of Los Angeles and Long Beach. Atmospheric Environment 43, 2960-2970.

LARIAC, 2009. Los Angeles Region Imagery Acuisition Consortium (LARIAC) data archives. Los Angeles County GIS Data Portal, Los Angeles.

Liu, C.-H., Barth, M.C., Leung, D.Y.C., 2004. Large-eddy simulation of flow and pollutant transport in street canyons of different building-height-street-width ratios Journal of Applied Meteorology 43, 1410-1424.

Marshall, J.D., McKone, T.E., Deakin, E., Nazaroff, W.W., 2005. Inhalation of motor vehicle emissions: effects of urban population and land area. Atmos. Environ. 39, 283-295.

Mills, J.B., Park, J.H., Peters, T.M., 2013. Comparison of the DiSCmini aerosol monitor to a handheld Condensation Particle Counter and a Scanning Mobility Particle Sizer for submicrometer sodium chloride and metal aerosols. Journal of Occupational and Environmental Hygiene 10, 250-258.

Morawska, L., Ristovski, Z., Jayaratne, E.R., Keogh, D.U., Ling, X., 2008. Ambient nano and ultrafine particles from motor vehicle emissions: Characteristics, ambient processing and implications on human exposure. Atmospheric Environment 42, 8113-8138.

Ning, Z., Geller, M.D., Moore, K.F., Sheesley, R., Schauer, J.J., Sioutas, C., 2007. Daily variation in chemical characterisitics of urban ultrafine aerosols and inference of their sources. Environmental Science \& Technology 41, 6000-6006.

Pearson, R.L., Wachtel, H., Ebi, K.L., 2000. Distance-weighted traffic density in proximity to a home is a risk factor for leukemia and other childhood cancers. J. Air Waste Manage. Assoc. 50, 175-180. 
Pirjola, L., Lähde, T., Niemi, J.V., Kousa, A., Rönkkö, T., Karjalainen, P., Keskinen, J., Frey, A., Hillamo, R., 2012. Spatial and temporal characterization of traffic emissions in urban microenvironments with a mobile laboratory. Atmospheric Environment 63, 156-167.

Ranasinghe, D., Choi, W., Winer, A.M., Paulson, S.E., 2015. Developing high spatial resolution concentration maps using mobile air quality measurements. Aerosol and Air Quality Research under review.

Ren, C., Wu, J., Chung, J.H., Delfino, R.J., Ritz, B., 2008. Association Between Local Traffic-generated Air Pollution and Preterm Delivery in the South Coast Air Basin of California. Epidemiology 19, S158S159.

Seibert, P., Beyrich, F., Gryning, S.E., Joffre, S., Rasmussen, A., Tercier, P., 2000. Review and intercomparison of operational methods for the determination of the mixing height. Atmospheric Environment 34, 1001-1027.

Tonne, C., Melly, S., Mittleman, M., Coull, B., Goldberg, R., Schwartz, J., 2007. A case-control analysis of exposure to traffic and acute myocardial infarction. Environ. Health Perspect. 115, 53-57.

Volk, H.E., Hertz-Picciotto, I., Delwiche, L., Lurmann, F., McConnell, R., 2011. Residential Proximity to Freeways and Autism in the CHARGE Study. Environ. Health Perspect. 119, 873-877.

Zhou, Y., Levy, J.I., 2007. Factors influencing the spatial extent of mobile source air pollution impacts: a meta-analysis. BMC Public Health 7. 

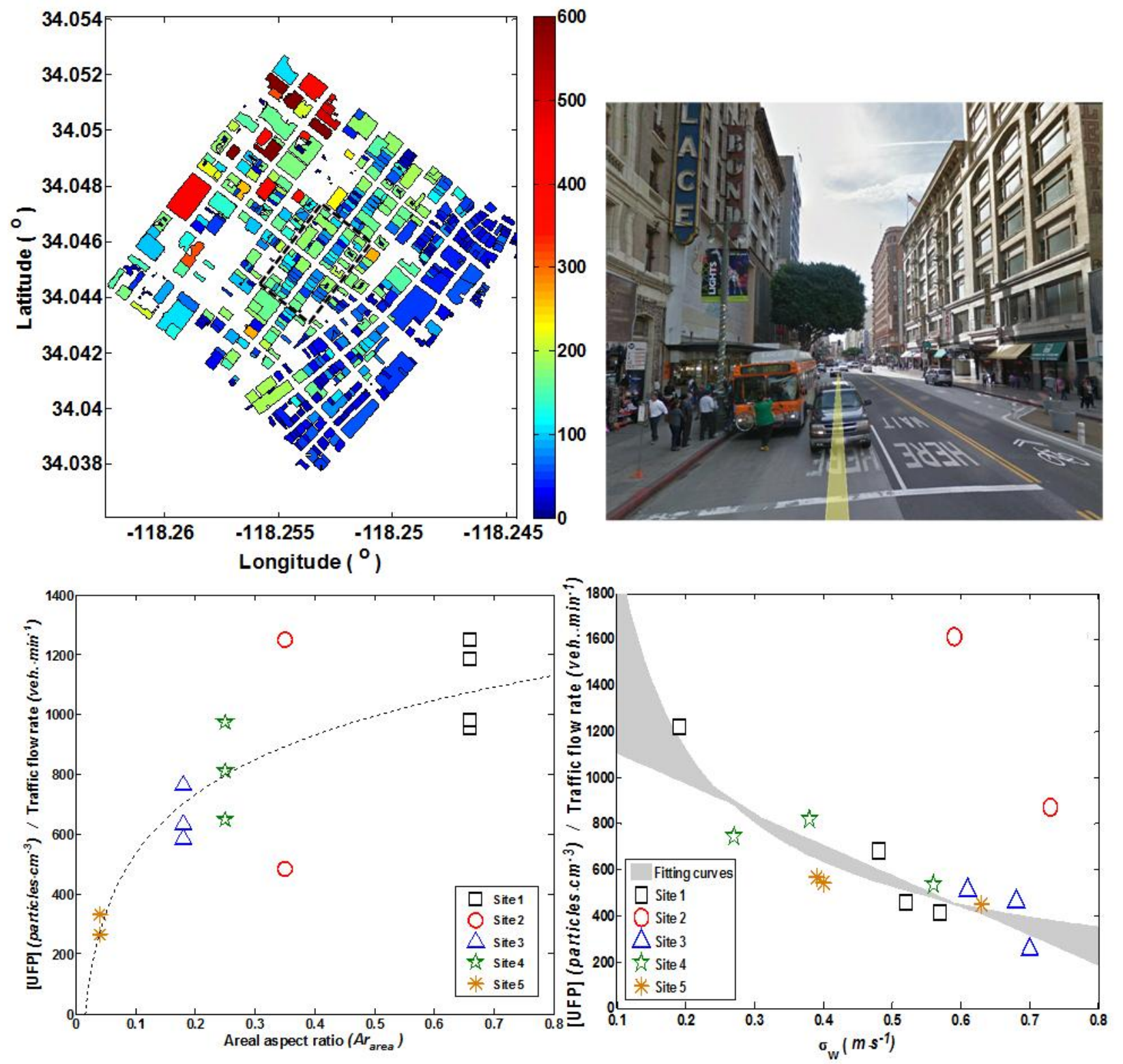